\title{
Multifactor Analysis of Roadheader's Body Pose Responses during the Horizontal Cutting Process
}

\author{
Kai Zong $(\mathbb{D}$, Peng Zhang $(\mathbb{D}$, Pengjiang Wang $(\mathbb{D}$, Shichen Fu $(\mathbb{D}$, \\ Yiming Li, Minjun Zhang $(\mathbb{D}$, and Miao Wu \\ School of Mechanical Electronic and Information Engineering, China University of Mining and Technology, Beijing 100083, China \\ Correspondence should be addressed to Kai Zong; zongkaiwd1991@163.com
}

Received 19 October 2017; Revised 31 January 2018; Accepted 25 February 2018; Published 4 April 2018

Academic Editor: Longjun Dong

Copyright (c) 2018 Kai Zong et al. This is an open access article distributed under the Creative Commons Attribution License, which permits unrestricted use, distribution, and reproduction in any medium, provided the original work is properly cited.

\begin{abstract}
Based on the Lagrange equation in system dynamics, aiming at the horizontal cutting process, the dynamical coupling model of boom-type roadheader's body pose was established. According to input problem of solving the model, a calculation method of the cutting head load was proposed, and the relationship between the cutting head load and pressure of the driving cylinders and swing angle of the cutting arm was obtained through simulating analysis. The simulation model was established to solve the dynamical coupling model. The cutting head load, horizontal swing angle of the cutting arm, and dip angle of coal seam were regarded as independent variables to perform changing parameter analysis in variations of the body pose. The field experiment was carried out, and the measured data is basically consistent with the simulation values. The results show that lateral displacement of the body can reach up to $6.5 \mathrm{~cm}$, backward displacement can reach up to $5.2 \mathrm{~cm}$, floor-based quantity can reach up to $11 \mathrm{~cm}$, pitch angle of the body can reach up to $7.8^{\circ}$, and roll angle can reach up to $2.1^{\circ}$. Variations of the body pose parameters are influenced greatly by the cutting head load, while the influence from horizontal swing angle of the cutting arm and dip angle of coal seam is slighter. Among the pose parameters, floor-based quantity and pitch angle of the body vary relatively greatly, which tend to seriously influence forming quality of the roadway and should be mainly considered in deviation rectification of the roadheader's body pose.
\end{abstract}

\section{Introduction}

Coal is the main energy source in China, accounting for $65 \%$ of China's primary energy consumption, which supports sustainable development of national economy and society. At present, the depth of coal mining in China keeps increasing, and some coal mines have exceeded $1000 \mathrm{~m}$; therefore coal mining faces more and more difficulty. The mining and excavating operation are the most important and difficult production links. There are high risk factors in deep coal seam, so it is very significant to study the key basic problems of the fully mechanized excavation face [1-6].

Boom-type roadheader is the most important equipment in the fully mechanized excavation face, mainly used for excavation of the roadway to prepare the working face for coal mining. Due to the complexity and changeableness of the occurrence condition and physical mechanical properties of coal and rock in roadway cross-section, the hardness of coal and rock during cutting process is changing constantly and randomly; therefore the cutting head load is also continuously changing during the cutting process [7-12]. The complex and changeable cutting head load, different dip angles of coal seam, and constantly changing horizontal swing angle of cutting arm cause constant change of roadheader's body pose during the horizontal cutting process, which seriously influences the positioning and orienting excavation of the roadheader and leads to reduction in forming quality and drivage efficiency of the roadway [13-16]. Therefore, study on the regularities of roadheader's body pose responses during the horizontal cutting process has great significance in improvement of forming quality and drivage efficiency of the roadway, realization of robotized automatic cutting, and ultimately realization of "unmanned" operation in the fully mechanized excavation face.

Some domestic and international scholars have done some researches on related aspects of roadheaders. Ergin 
and Acaroglu and Acaroglu and Erdogan established the mathematical model of the cutting system of a longitudinal axial roadheader during the horizontal cutting process and obtained the three-dimension forces on the cutting head through theoretical calculation and field test methods, then analyzed stability of the cutting system during cutting process and the influencing factors through simulations, and finally ascertained the maximum working range of the cutting system under stable state $[17,18]$. Jang et al. and Chen et al. analyzed dynamical behaviors of the execution system of a boom-type roadheader during cutting process through the method of multi-rigid-body dynamics modeling and simulation and designed the attachments of the cutting head in order to improve the cutting performance of roadheader $[19,20]$. Li et al. and Zhao et al. established the overall dynamical model of a boom-type roadheader based on the Lagrange equation, constructed the theoretical virtual cutting head load, and analyzed the vibration characteristics of the overall unit system during the horizontal process and obtained the results of vibration frequency and amplitude responses [21, 22]. Du et al. and Fu et al. built a measurement system based on the intersectional lasers, laser target, and calculation method of roadheader's body pose to carry out real-time measurement of roadheader's body pose when it moves in the roadway during the cutting process, and verified the system and method through experiment $[23,24]$.

In conclusion, some researches conducted on dynamical behaviors of key mechanisms of the boom-type roadheader during cutting process, vibration characteristics of the overall unit, and measurement of the body pose have been certainly achieved. However, research on the regularities of roadheader's body pose responses under influence of various factors during cutting process is still vacant. Based on EBZ160 type roadheader, aiming at the horizontal cutting process and the three factors of the cutting head load, horizontal swing angle of cutting arm, and dip angle of coal seam, this paper is going to analyze the regularities of roadheader's body pose responses through overall unit dynamical modeling and simulation.

\section{Dynamical Coupling Model of the Body Pose}

\subsection{Overall Mechanical Analysis during the Horizontal Cutting} Process. Theoretically, due to the extremely complex working environment of coal mine, the boom-type roadheader should be a system with infinite degree of freedom during the horizontal cutting process. Therefore, in order to establish the dynamical coupling model of roadheader's body pose, it is necessary to make reasonable and appropriate simplification and assumption for the working state of roadheader [25-27].

According to the actual structure and working environment of roadheader, its working state is simplified and assumed as follows.

(1) In general, the quality distribution of the parts of roadheader is relatively uniform and the elasticity is small, so the elasticity can be ignored and the overall unit can be simplified as concentrated quality: quality of cutting head $m_{1}$,

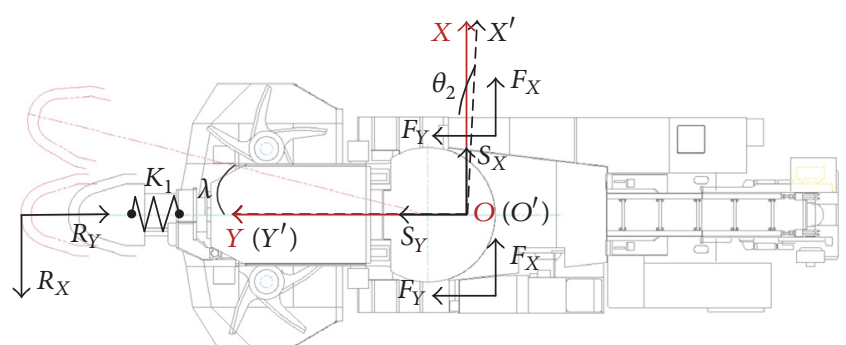

FIGURE 1: The coordinate system in vertical view of the overall machine.

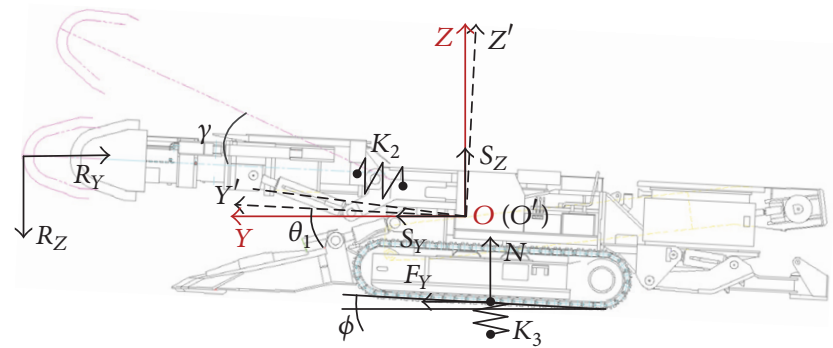

FIGURE 2: The coordinate system in left view of the overall machine.

quality of the cutting arm $m_{2}$, and quality of the body $m_{3}$ (including the travelling mechanism).

(2) Assuming that the parts of roadheader are connected by massless elastic element, the rigidity coefficient between the cutting head and the cutting arm is expressed by $K_{1}$, the rigidity coefficient between the cutting arm and the body is expressed by $K_{2}$, and the rigidity coefficient between the body and the bottom ground is expressed by $K_{3}$.

(3) Assuming that the damping between all parts of roadheader is viscous damping, the damping between the cutting head and the cutting arm is expressed by $C_{1}$, the damping between the cutting arm and the body is expressed by $C_{2}$, and the damping between the body and the bottom ground is expressed by $C_{3}$.

(4) The cutting head load can be simplified as threedimension forces, namely, the force in the horizontal direction, the force in the vertical direction, and the force perpendicular to the coal wall.

Take the initial position of roadheader's center of gravity as the origin to establish a three-dimensional fixed rectangular coordinate system $O X Y Z$, and take the roadheader's center of gravity as the origin to establish a moving coordinate system $O^{\prime} X^{\prime} Y^{\prime} Z^{\prime}$ fixed on the body and moving with the body, as shown in Figures 1 and 2. The $x$-axis is in the horizontal direction, the $y$-axis is perpendicular to the coal wall, and the $z$-axis is in the vertical direction.

In Figure $1, \lambda$ is the horizontal swing angle of the cutting arm relative to the body, $\theta_{2}$ is the roll angle of the body, $S_{X}$ is displacement of the body in the $x$-axis direction, and $S_{Y}$ is displacement of the body in the $y$-axis direction; $R_{X}$ is the component force of the cutting head load in the horizontal direction, $R_{Y}$ is the component force of the cutting head load perpendicular to the coal wall, and $F_{X}$ is the friction force 
between the crawler and the bottom ground in the $x$-axis direction. $F_{Y}$ is the friction force between the crawler and the bottom ground in the $y$-axis direction. In Figure 2, $\gamma$ is the vertical swing angle of the cutting arm relative to the body, $\theta_{1}$ is the pitch angle of the body, $S_{Z}$ is displacement of the body in the $z$-axis direction, $R_{Z}$ is the component force of the cutting head load in the vertical direction, and $\varphi$ is the dip angle of coal seam.

2.2. Dynamical Coupling Model. Since a roadheader can be considered as a complete system during cutting process, the differential equations of roadheader's body pose can be established based on the Lagrange equation in system dynamics, so as to accurately describe the overall unit dynamical behaviors of roadheader during the horizontal cutting process.

The second-kind Lagrange equation in system dynamics [28] is

$$
\frac{d}{d t}\left(\frac{\partial T}{\partial \dot{q}_{i}}\right)-\frac{\partial T}{\partial q_{i}}=Q_{i}
$$

Considering viscous resistance, Rayleigh dissipation function $D$ is introduced into the Lagrange equation:

$$
\frac{d}{d t}\left(\frac{\partial T}{\partial \dot{q}_{i}}\right)-\frac{\partial T}{\partial q_{i}}+\frac{\partial D}{\partial \dot{q}_{i}}=Q_{i} .
$$

Separating the potential forces from the right side of (2), which is to introduce the energy function $U(q i),(2)$ can be furtherly transformed into:

$$
\frac{d}{d t}\left(\frac{\partial T}{\partial \dot{q}_{i}}\right)-\frac{\partial T}{\partial q_{i}}+\frac{\partial D}{\partial \dot{q}_{i}}+\frac{\partial U}{\partial q_{i}}=Q_{i} .
$$

In (3), $T$ is the kinetic energy of the system, $D$ is the dissipative energy, $U$ is the potential energy, $q i$ is the generalized coordinate, $i$ is the number of generalized coordinates, and $Q i$ is the generalized force.

Based on the Lagrange equation (3), the dynamical coupling model of roadheader's body pose is going to be established through energy method in following part:

$$
\begin{aligned}
\frac{d}{d t}\left(\frac{\partial T}{\partial \dot{S}_{X}}\right) & =\left(m_{1}+m_{2}+m_{3}\right) \ddot{S}_{X}-\left(m_{1} L+m_{2} L_{y}\right) \cos \gamma\left(\ddot{\lambda} \cos \lambda-\dot{\lambda}^{2} \sin \lambda\right), \\
\frac{\partial T}{\partial S_{X}} & =0, \\
\frac{\partial D_{H}}{\partial \dot{S}_{X}}= & C_{1} \frac{\sin ^{2} \theta_{2}}{\cos ^{2} \gamma} \dot{S}_{X}+C_{1} \frac{\sin \theta_{2}\left[\dot{S}_{Y} \sin \left(\varphi-\theta_{1}\right)+\dot{S}_{Z} \cos \left(\varphi-\theta_{1}\right)\right]}{\cos ^{2} \gamma}, \\
\frac{\partial U_{H}}{\partial S_{X}}= & \left(m_{1}+m_{2}+m_{3}\right) g \sin \theta_{2}+K_{1} \frac{\sin ^{2} \theta_{2}}{\cos ^{2} \gamma} S_{X} \\
& +K_{1} \frac{\sin \theta_{2}\left[L \sin \left(\gamma+\varphi-\theta_{1}\right)-L \sin (\gamma+\varphi)-b \sin \theta_{2}+S_{Y} \sin \left(\varphi-\theta_{1}\right)+S_{Z} \cos \left(\varphi-\theta_{1}\right)\right]}{\cos ^{2} \gamma} .
\end{aligned}
$$

The above equations are plugged into (3), and then the differential equation of motion to describe $S_{X}$ was derived as

$$
\begin{aligned}
& \left(m_{1}+m_{2}+m_{3}\right) \ddot{S}_{X}+C_{1} \frac{\sin ^{2} \theta_{2}}{\cos ^{2} \gamma} \dot{S}_{X}+K_{1} \frac{\sin ^{2} \theta_{2}}{\cos ^{2} \gamma} S_{X}+\left(m_{1}+m_{2}+m_{3}\right) g \sin \theta_{2}-\left(m_{1} L+m_{2} L_{y}\right) \cos \gamma\left(\ddot{\lambda} \cos \lambda-\dot{\lambda}^{2} \sin \lambda\right) \\
& +\frac{\left\{C_{1} \sin \theta_{2}\left[\dot{S}_{Y} \sin \left(\varphi-\theta_{1}\right)+\dot{S}_{Z} \cos \left(\varphi-\theta_{1}\right)\right]+K_{1} \sin \theta_{2}\left[L \sin \left(\gamma+\varphi-\theta_{1}\right)-L \sin (\gamma+\varphi)-b \sin \theta_{2}+S_{Y} \sin \left(\varphi-\theta_{1}\right)+S_{Z} \cos \left(\varphi-\theta_{1}\right)\right]\right\}}{\cos ^{2} \gamma} \\
& =R_{X}+F_{X} .
\end{aligned}
$$

In the same way, the differential equations of motion to describe $S_{Y}, S_{Z}, \theta_{1}$, and $\theta_{2}$ were derived as follows: 


$$
\begin{aligned}
& \left(m_{1}+m_{2}+m_{3}\right) \ddot{S}_{Y}+C_{1} \frac{\sin ^{2}\left(\varphi-\theta_{1}\right)}{\cos ^{2} \gamma} \dot{S}_{Y}+K_{1} \frac{\sin ^{2}\left(\varphi-\theta_{1}\right)}{\cos ^{2} \gamma} S_{Y}+\left(m_{1}+m_{2}+m_{3}\right) g \sin \left(\varphi-\theta_{1}\right)-\left(m_{1} L+m_{2} L_{y}\right) \cos \gamma\left(\ddot{\lambda} \sin \lambda-\dot{\lambda}^{2} \cos \lambda\right) \\
& +\frac{\left\{C_{1} \sin \left(\varphi-\theta_{1}\right)\left[\dot{S}_{Z} \cos \left(\varphi-\theta_{1}\right)+\dot{S}_{X} \sin \theta_{2}\right]+K_{1} \sin \left(\varphi-\theta_{1}\right)\left[L \sin \left(\gamma+\varphi-\theta_{1}\right)-L \sin (\gamma+\varphi)-b \sin \theta_{2}+S_{Z} \cos \left(\varphi-\theta_{1}\right)+S_{X} \sin \theta_{2}\right]\right\}}{\cos ^{2} \gamma}=R_{Y} \\
& +F_{Y} \\
& \left(m_{1}+m_{2}+m_{3}\right) \ddot{S}_{Z}+\left[2 C_{3}+C_{1} \frac{\cos ^{2}\left(\varphi-\theta_{1}\right)}{\cos ^{2} \gamma}\right] \dot{S}_{Z}+\left[2 K_{3}+K_{1} \frac{\cos ^{2}\left(\varphi-\theta_{1}\right)}{\cos ^{2} \gamma}\right] S_{Z}-\left(m_{1} L+m_{2} L_{y}\right)\left(\ddot{\lambda} \sin \lambda-\dot{\lambda}^{2} \cos \lambda\right)+\left(m_{1}+m_{2}+m_{3}\right) g \\
& \cdot \cos \left(\varphi-\theta_{1}\right)+a K_{3} \theta_{2}+b K_{3} \theta_{1}+a C_{3} \dot{\theta}_{2}+b C_{3} \dot{\theta}_{1} \\
& +\frac{\left\{C_{1} \cos \left(\varphi-\theta_{1}\right)\left[\dot{S}_{Y} \sin \left(\varphi-\theta_{1}\right)+\dot{S}_{X} \sin \theta_{2}\right]+K_{1} \cos \left(\varphi-\theta_{1}\right)\left[L \sin \left(\gamma+\varphi-\theta_{1}\right)-L \sin (\gamma+\varphi)-b \sin \theta_{2}+S_{Y} \sin \left(\varphi-\theta_{1}\right)+S_{X} \sin \theta_{2}\right]\right\}}{\cos ^{2} \gamma}=R_{Z} \\
& +N+G \\
& J_{X} \ddot{\theta}_{1}+b^{2} C_{3} \dot{\theta}_{1}+b^{2} K_{3} \theta_{1}+\left(m_{1}+m_{2}+m_{3}\right) g\left[S_{Z} \sin \left(\varphi-\theta_{1}\right)-S_{Y} \cos \left(\varphi-\theta_{1}\right)\right]-\left(m_{2}+m_{3}\right) g L_{\alpha} \cos \left(\alpha+\varphi-\theta_{1}\right)-\left(m_{1} L+m_{2} L_{y}\right) g \cos \left(\gamma+\varphi-\theta_{1}\right) \\
& +K_{1} \\
& \frac{\left[L \sin \left(\gamma+\varphi-\theta_{1}\right)-L \sin (\gamma+\varphi)-b \sin \theta_{2}+S_{Y} \sin \left(\varphi-\theta_{1}\right)+S_{Z} \cos \left(\varphi-\theta_{1}\right)+S_{X} \sin \theta_{2}\right]\left[S_{Z} \sin \left(\varphi-\theta_{1}\right)-L \cos \left(\gamma+\varphi-\theta_{1}\right)-S_{Y} \cos \left(\varphi-\theta_{1}\right)\right]}{\cos ^{2} \gamma} \\
& +b C_{3} \dot{S}_{Z}+b K_{3} S_{Z}=M_{\theta_{1}} \\
& J_{Y} \ddot{\theta}_{2}+a^{2} C_{3} \dot{\theta}_{2}+a^{2} K_{3} \theta_{2}+\left[\left(m_{1}+m_{2}+m_{3}\right) g S_{X}-\left(m_{1}+m_{2}\right) g b\right] \cos \theta_{2}+K_{1} \\
& \text {. } \frac{\cos \theta_{2}\left(S_{X}-b\right)\left[L \sin \left(\gamma+\varphi-\theta_{1}\right)-L \sin (\gamma+\varphi)-b \sin \theta_{2}+S_{Y} \sin \left(\varphi-\theta_{1}\right)+S_{Z} \cos \left(\varphi-\theta_{1}\right)+S_{X} \sin \theta_{2}\right]}{\cos ^{2} \gamma}+a C_{3} \dot{S}_{Z}+a K_{3} S_{Z}=M_{\theta_{2}} \text {. }
\end{aligned}
$$

Equations (5) and (6) are the dynamical coupling model of roadheader's body pose. In the equations, $L$ is the distance between the center of gyration of the cutting arm and the center of gyration of the cutting head, $L_{y}$ is the distance between the center of gravity of the cutting arm and its center of gyration, $J_{X}$ is the moment of inertia of the body about the $x$-axis, $J_{Y}$ is the moment of inertia of the body about the $y$ axis, a is $1 / 2$ of the width of the body, $b$ is $1 / 2$ of the length of the body $f, G$ is the gravity of roadheader, $N$ is the bearing reaction on roadheader from the bottom ground, $M_{\theta 1}$ is the resultant moment of the system corresponding to $\theta_{1}$, and $M_{\theta 2}$ is the resultant moment of the system corresponding to $\theta_{2}$.

\section{Calculation Method of the Cutting Head Load}

According to (5) and (6), the cutting head load must firstly be obtained as the initial input quantity to solve the dynamical coupling model of the roadheader's body pose. With the complexity and changeableness situation of the cutting head load, it is difficult to obtain the cutting head load spectrum directly in the field, and the spectrum obtained by individual researchers is too complex and irregular to process and utilize efficiently. Aiming at the present situation, a method is proposed to calculate the cutting head load in this paper.

The cutting arm of roadheader is driven by a pair of angling cylinders during the horizontal cutting process and driven by a pair of lifting cylinders during the vertical cutting process. The pressure of angling cylinders and lifting cylinders is changing with different hardness of coal and rock, and there is a positive correlation between them [22, 29]. The pressure of angling cylinders and lifting cylinders can be accurately measured by sensors; therefore, the breaking forces of the cutting head to the coal wall can be calculated according to the pressure of cylinders. According to Newton's third law, the breaking forces are equal to the cutting head load.

3.1. The Component Force in the Horizontal Direction. The cutting arm is fixedly connected to the revolving platform and driven by a pair of symmetrically arranged cylinders. The cylinder pole is connected to the revolving platform and the cylinder barrel is connected to the frame. At work, the cylinder on one side is elongated and the cylinder on the other side is shortened synchronously, and the synergistic motion drives the revolving platform to revolve, leading the cutting arm to swing around its center of gyration. As shown in Figure 3, the center of gyration of the revolving platform is point $O$, the hinge point of the cylinder pole and the revolving platform is point $A$, the hinge point of right cylinder barrel and the frame is point $B$, the hinge point of left cylinder barrel and the frame is point $C$, the hinge point of left cylinder pole and the revolving platform is point $D$, and the force bearing point of the cutting head is point $R$. The gyration radius of the revolving platform is $O A=O D=r, O B=O C=l_{1}, O R=L_{1}$, and $\angle A O B=\angle C O D=\alpha$. After the cutting arm swings beyond a certain angle $\lambda$, point $A$ has moved to point $A^{\prime}$, point $D$ has moved to point $D^{\prime}, C D^{\prime}=l_{2}$, and $A^{\prime} B=l_{3}$.

Take the horizontal swing process towards the right side as an example. As the cutting arm swinging horizontally 


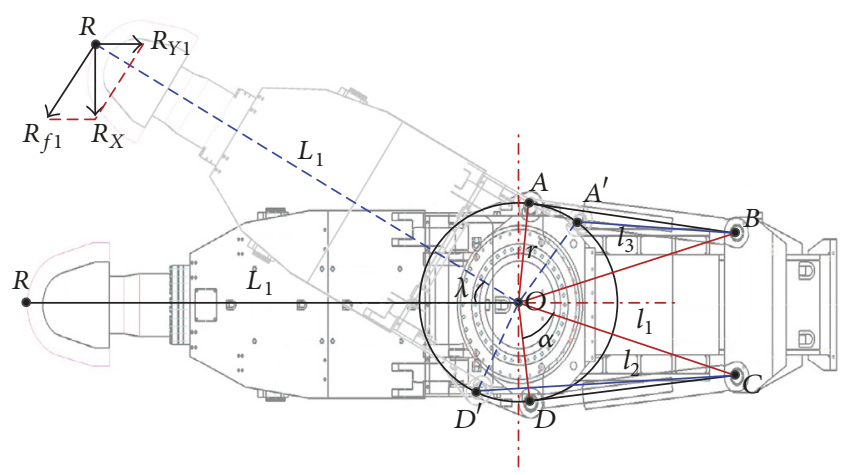

Figure 3: Two-dimensional diagram of the cutting arm during the horizontal swing process.

towards the right, the component force of the cutting head load in the horizontal direction presents towards the left. During this process, the hydraulic oil is entering into the head port of the left cylinder to push the revolving platform, and the hydraulic oil is entering into the rod port of the right cylinder to pull the revolving platform. When the cutting arm swings towards the left, the force condition is oppositely symmetrical to the above analysis.

Taking the center of the revolving platform as the base point $O$, the moment of push force of the left cylinder about the point $O$ is

$$
M_{T}=P_{1} S_{1} \frac{r l_{1} \sin (\alpha+\lambda)}{l_{2}} .
$$

The moment of pull force of the right cylinder about the point $O$ is

$$
M_{L}=P_{1}\left(S_{1}-S_{2}\right) \frac{r l_{1} \sin (\alpha-\lambda)}{l_{3}} .
$$

The moment of the cutting head load about the point $O$ is

$$
M_{1}=R_{f 1} L_{1} \cos \gamma .
$$

The revolving platform bears a large unilateral pressure while the roadheader is drilling into the coal wall, but the pressure to the revolving platform is very small and relatively dispersed during the section cutting process. The revolving platform and its support are connected with sufficiently lubricated rolling bearing. Therefore, the friction moment of the revolving platform itself is negligible relative to the driving force of the cylinder and the resistance of the coal wall to the cutting head.

According to (7), (8), and (9), the circumferential force of the cutting head in the horizontal direction is

$$
\begin{aligned}
& R_{f 1} \\
& \quad=\frac{P_{1} r l_{1}\left[l_{3} S_{1} \sin (\alpha+\lambda)+l_{2}\left(S_{1}-S_{2}\right) \sin (\alpha-\lambda)\right]}{l_{2} l_{3} L_{1} \cos \gamma} .
\end{aligned}
$$

In the above formula, $P_{1}$ is the pressure of the angling cylinders, $S_{1}$ is the cross-sectional area of the cylinder diameter, and $S_{2}$ is the cross-sectional area of the pole diameter.

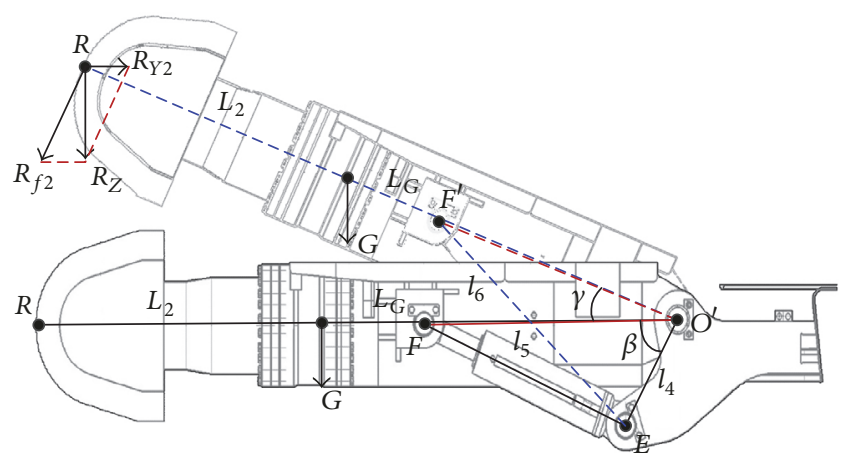

FIGURE 4: Two-dimensional diagram of the cutting arm during the vertical swing process.

The component force of the cutting head load in the horizontal direction is

$$
\begin{aligned}
& R_{X}=R_{f 1} \cos \lambda \\
& =\frac{P_{1} r l_{1} \cos \lambda\left[l_{3} S_{1} \sin (\alpha+\lambda)+l_{2}\left(S_{1}-S_{2}\right) \sin (\alpha-\lambda)\right]}{l_{2} l_{3} L_{1} \cos \gamma} .
\end{aligned}
$$

3.2. The Component Force in the Vertical Direction. The cutting arm is driven by a pair of lifting cylinders arranged parallelly and symmetrically to each other during the vertical swing. The cylinder pole is connected to the cutting arm and the cylinder barrel is connected to the revolving platform. At work, lifting cylinders are elongated or shortened synchronously, driving the cutting arm to swing up or down. As shown in Figure 4, the hinge point between the cutting arm and revolving platform is point $O^{\prime}$, the hinge point of the cylinder barrel and the revolving platform is point $E$, the hinge point of the cylinder pole and the cutting arm is point $F$, and the force bearing point of the cutting head is point $R$. The distance between the center of gravity of the cutting arm and point $O^{\prime}$ is $L_{G}, O^{\prime} E=l_{4}, O^{\prime} F=l_{5}, O^{\prime} R=L_{2}$, and $\angle E O^{\prime} F$ $=\beta$. After the cutting arm swings beyond a certain angle $\gamma$, point $F$ has moved to point $F^{\prime}$, and $E F^{\prime}=l_{6}$.

Take the vertical upward swing process as an example. With the cutting arm swinging vertically upward, the component force of the cutting head load in the vertical direction presents downward, and the hydraulic oil is entering into the head port of the lifting cylinders to push the cutting arm to swing upward. When the cutting arm swings downward, the force condition is oppositely symmetrical.

Taking the hinge point $O^{\prime}$ between the cutting arm and revolving platform as the base point, the moment of the cutting head load about the point $O^{\prime}$ is

$$
M_{2}=R_{f 2} L_{2} \cos \lambda
$$

The moment of the gravity of the cutting arm about the point $O^{\prime}$ is

$$
M_{G}=\left(m_{1}+m_{2}\right) g L_{G} \cos \lambda \cos \gamma .
$$


The moment of push force of the lifting cylinders about the point $O^{\prime}$ is

$$
M_{S}=2 P_{2} S_{3} \frac{l_{4} l_{5} \sin (\gamma+\beta)}{l_{6}}
$$

According to (12), (13), and (14), the circumferential force of the cutting head in the vertical direction is

$$
R_{f 2}=\frac{2 P_{2} S_{3} l_{4} l_{5} \sin (\gamma+\beta)}{l_{6} L_{2} \cos \lambda}-\frac{\left(m_{1}+m_{2}\right) g L_{G} \cos \gamma}{L_{2}} .
$$

In the above formula, $P_{2}$ is the pressure of the lifting cylinders, and $S_{3}$ is the cross-sectional area of the cylinder diameter.

The component force of the cutting head load in the vertical direction is

$$
\begin{aligned}
R_{Z}= & R_{f 2} \cos \gamma \\
= & \frac{2 P_{2} S_{3} l_{4} l_{5} \cos \gamma \sin (\gamma+\beta)}{l_{6} L_{2} \cos \lambda} \\
& -\frac{\left(m_{1}+m_{2}\right) g L_{G} \cos ^{2} \gamma}{L_{2}} .
\end{aligned}
$$

\subsection{The Component Force Perpendicular to the Coal Wall.} The component force of the cutting head load perpendicular to the coal wall can be calculated through addition of the component forces of the circumferential forces in the horizontal and vertical direction. As shown in Figure 3, the circumferential force of the cutting head in the horizontal direction is $R_{f 1}$, and its component force perpendicular to the coal wall is

$$
\begin{aligned}
& R_{Y 1}=R_{f 1} \sin \lambda \\
& =\frac{P_{1} r l_{1} \sin \lambda\left[l_{3} S_{1} \sin (\alpha+\lambda)+l_{2}\left(S_{1}-S_{2}\right) \sin (\alpha-\lambda)\right]}{l_{2} l_{3} L_{1} \cos \gamma} .
\end{aligned}
$$

As shown in Figure 4, the circumferential force of the cutting head in the vertical direction is $R_{f 2}$, and its component force perpendicular to the coal wall is

$$
\begin{aligned}
R_{Y 2}= & R_{f 2} \sin \gamma \\
= & \frac{2 P_{2} S_{3} l_{4} l_{5} \sin \gamma \sin (\gamma+\beta)}{l_{6} L_{2} \cos \lambda} \\
& -\frac{\left(m_{1}+m_{2}\right) g L_{G} \sin \gamma \cos \gamma}{L_{2}} .
\end{aligned}
$$

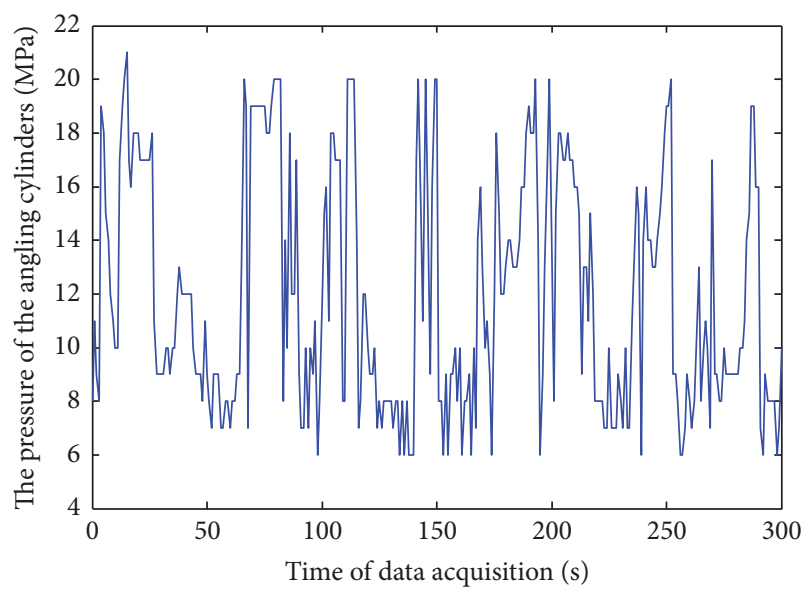

FIGURE 5: The pressure of the angling cylinders.

In summary, the component force of the cutting head load perpendicular to the coal wall is

$$
\begin{aligned}
R_{Y}= & R_{Y 1}+R_{Y 2} \\
= & \frac{P_{1} r l_{1} \sin \lambda\left[l_{3} S_{1} \sin (\alpha+\lambda)+l_{2}\left(S_{1}-S_{2}\right) \sin (\alpha-\lambda)\right]}{l_{2} l_{3} L_{1} \cos \gamma} \\
& +\frac{2 P_{2} S_{3} l_{4} l_{5} \sin \gamma \sin (\gamma+\beta)}{l_{6} L_{2} \cos \lambda} \\
& -\frac{\left(m_{1}+m_{2}\right) g L_{G} \sin \gamma \cos \gamma}{L_{2}} .
\end{aligned}
$$

3.4. The Calculation Results of the Cutting Head Load. Based on underground engineering experiment, the pressure data of angling cylinders and lifting cylinders on the EBZ-160 type roadheader was acquired by the BYD-60 type mining explosion-proof pressure transmitter, and the experiment data was processed. During the cutting process, the pressure of angling cylinders is changing in the range of $5 \sim 21 \mathrm{MPa}$, as shown in Figure 5. According to the pressure of angling cylinders and horizontal swing angle of the cutting arm, the component force $R_{X}$ of the cutting head load in the horizontal direction was simulated and calculated, and the result is shown in Figure 6. The pressure of lifting cylinders is changing in the range of $8 \sim 21 \mathrm{MPa}$, as shown in Figure 7. According to the pressure of lifting cylinders and vertical swing angle of the cutting arm, the component force $R_{Z}$ of the cutting head load in the vertical direction was simulated and calculated, and the result is shown in Figure 8. According to the pressures of angling cylinders and lifting cylinders, the component force $R_{Y}$ of the cutting head load perpendicular to the coal wall was simulated and calculated, and the result is shown in Figure 9.

\section{Simulation and Analysis}

4.1. Simulink Model and Initial Conditions Setting. According to the dynamical coupling model of roadheader's 


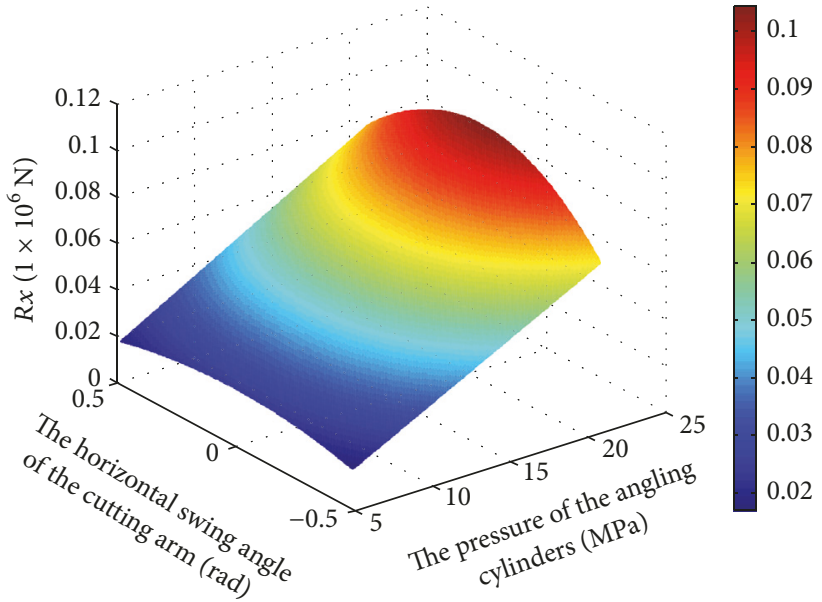

FIGURE 6: The component force $R_{X}$ of the cutting head load in the horizontal direction.

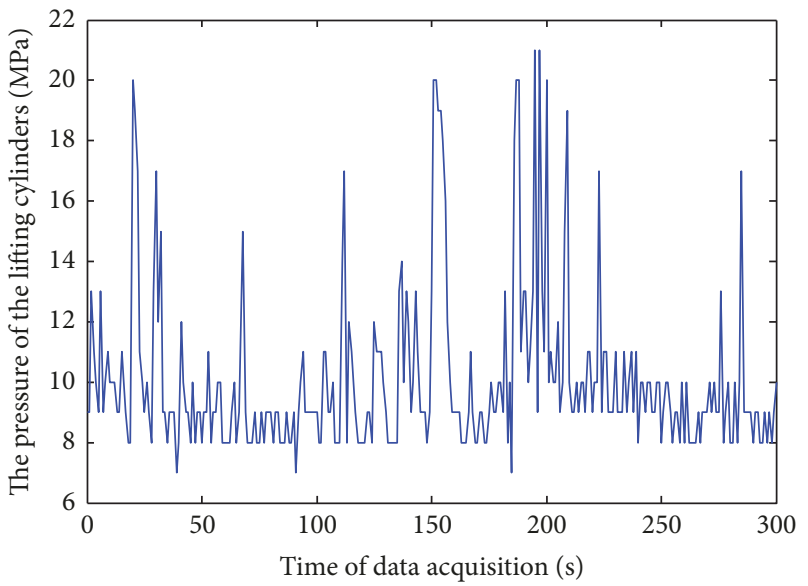

FIGURE 7: The pressure of the lifting cylinders.

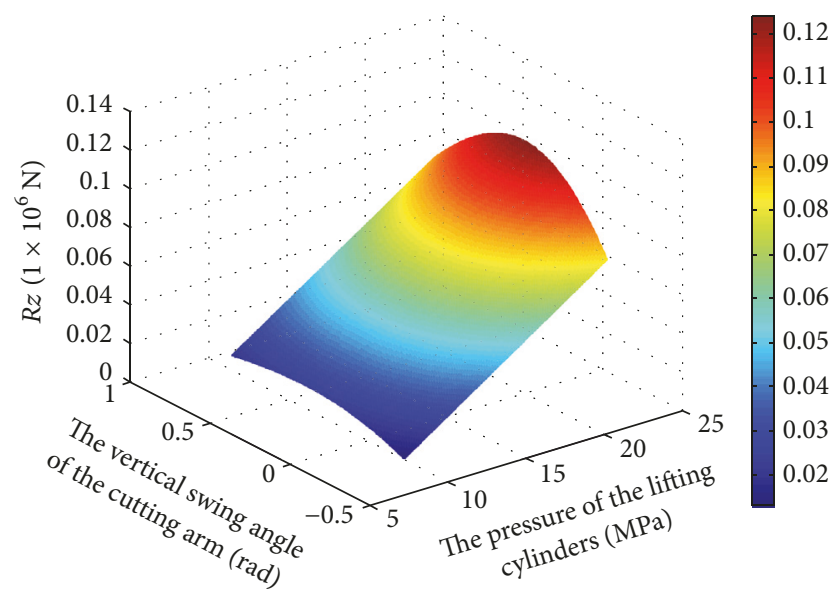

FIgURE 8: The component force $R_{Z}$ of the cutting head load in the vertical direction.

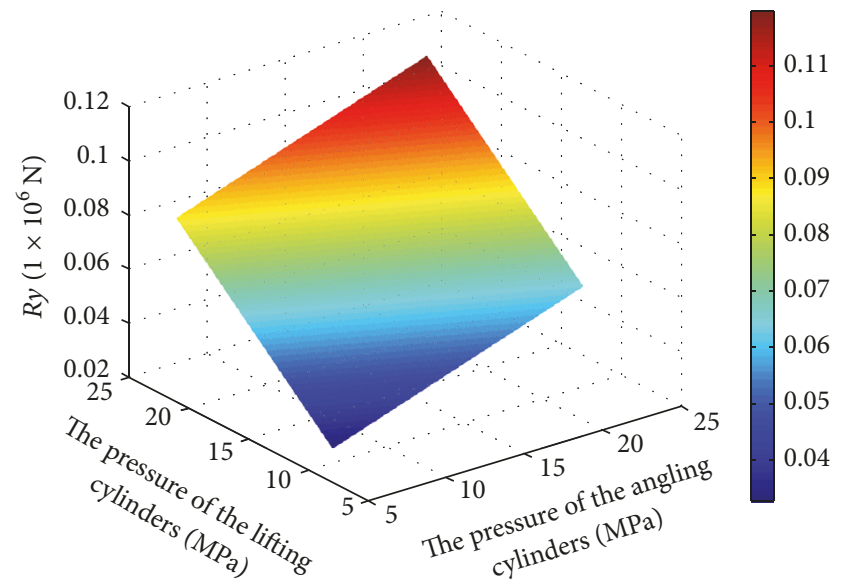

FIgURE 9: The component force $R_{Y}$ of the cutting head load perpendicular to the coal wall.

body pose during the horizontal cutting process, namely, (5) and (6), the simulation model to solve the differential equations was established in Simulink, as shown in Figure 10.

The horizontal swing process of EBZ160 type roadheader's cutting arm has the characteristic of axial symmetry, and the maximum of the swing angle is $28^{\circ}$ in both left and right side. In coalfields of different areas, the dip angle of coal seam is different, but it is no more than $15^{\circ}$ in most areas [30], and the maximum of the dip angle of coal seam adapted for EBZ160 type roadheader is $18^{\circ}$. Therefore, five positions of the cutting arm and five dip angles of coal seam are selected to perform changing parameter analysis of roadheader's body pose responses during the horizontal cutting process. The five positions of the cutting arm are expressed by $\lambda=0, \lambda=8^{\circ}, \lambda=$ $14^{\circ}, \lambda=20^{\circ}$, and $\lambda=28^{\circ}$, and the five dip angles of coal seam 


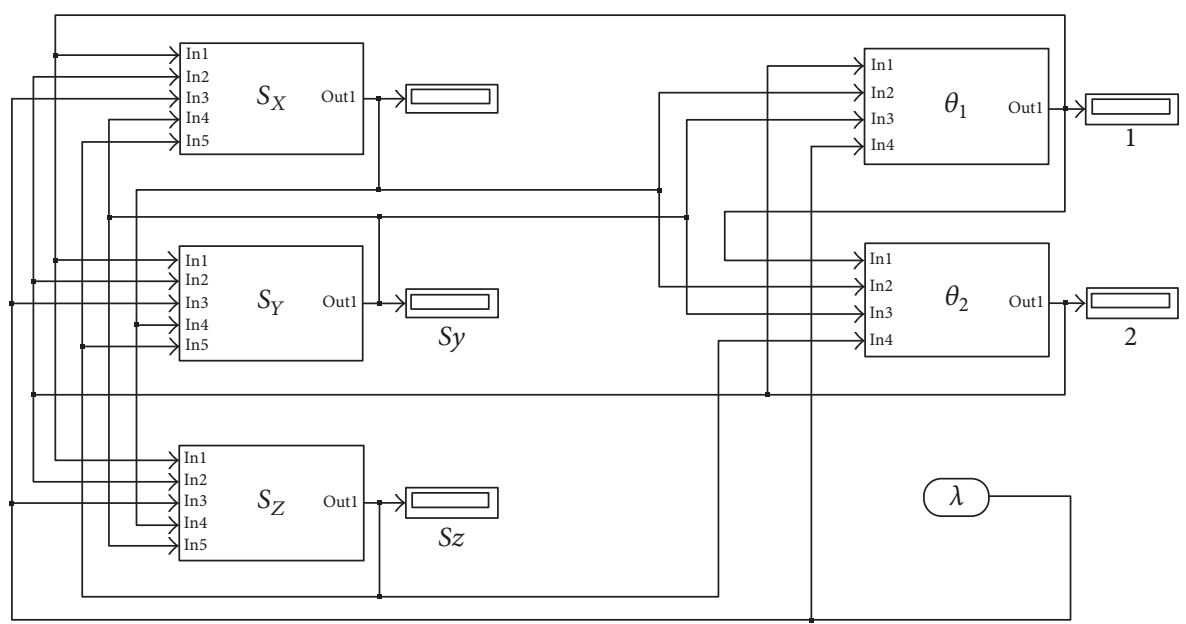

(a) The simulation system to solve roadheader's body pose

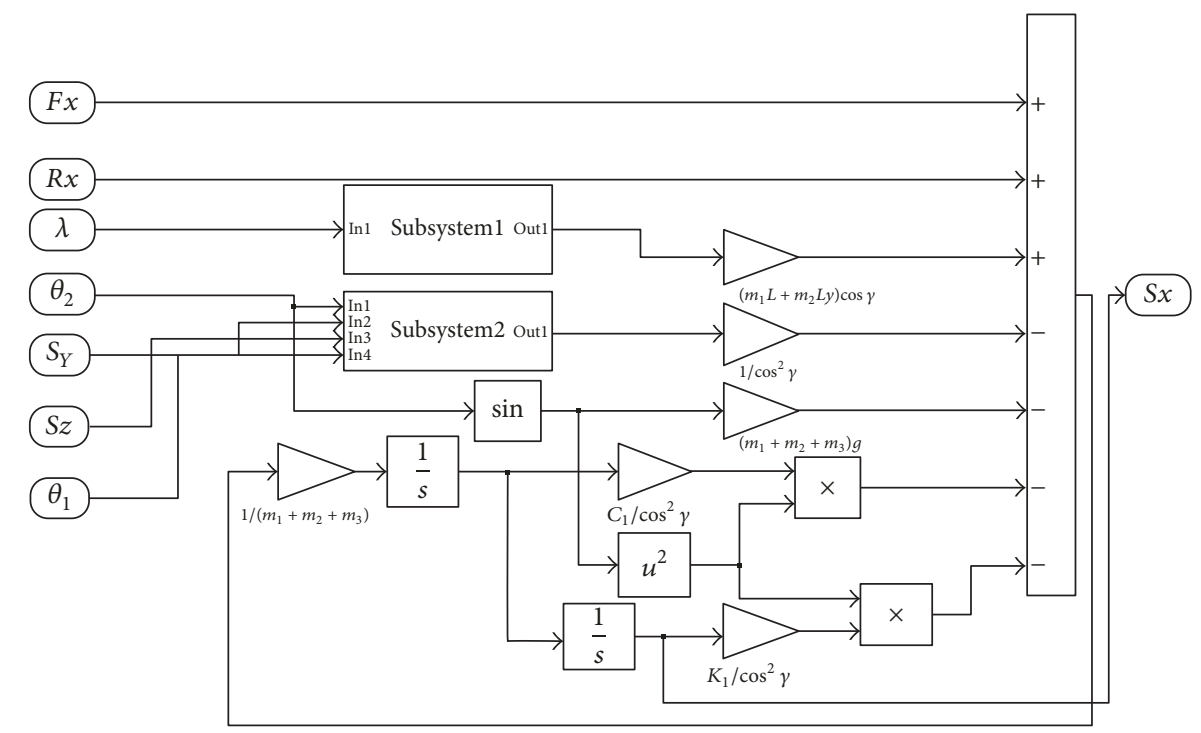

(b) The simulation model to solve $S_{X}$

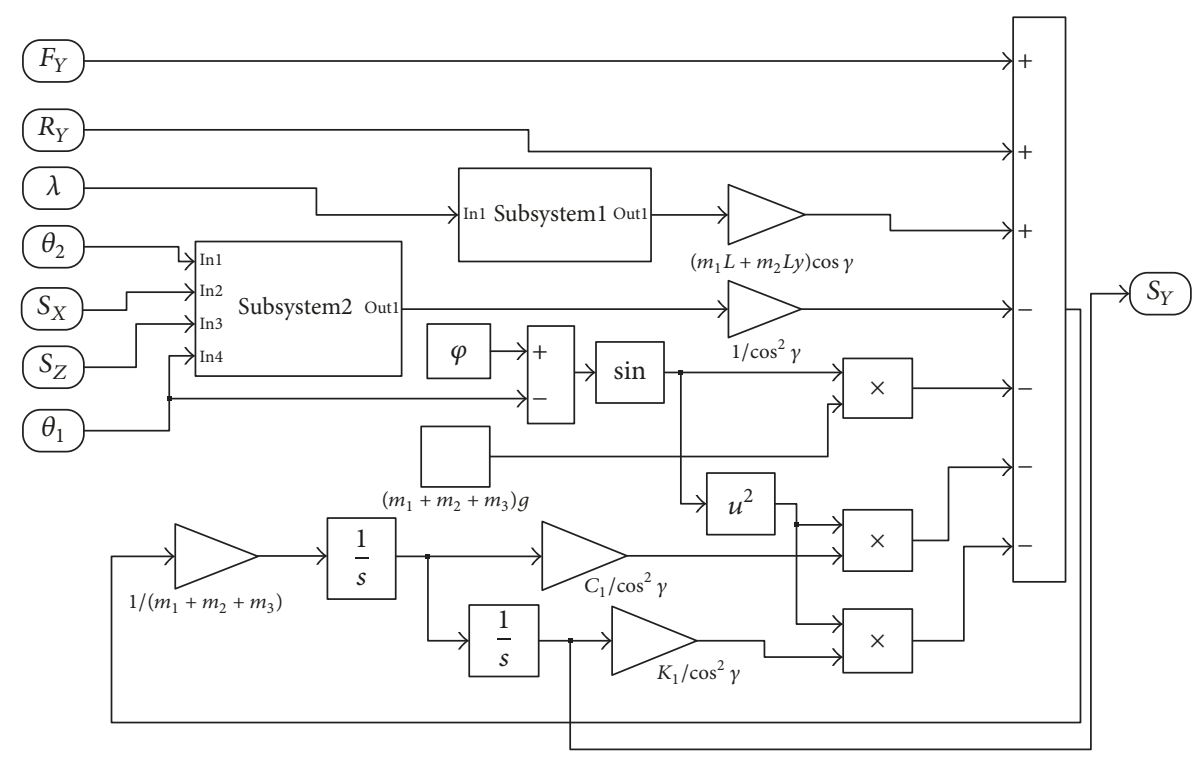

(c) The simulation model to solve $S_{Y}$

FIGURE 10: Continued. 


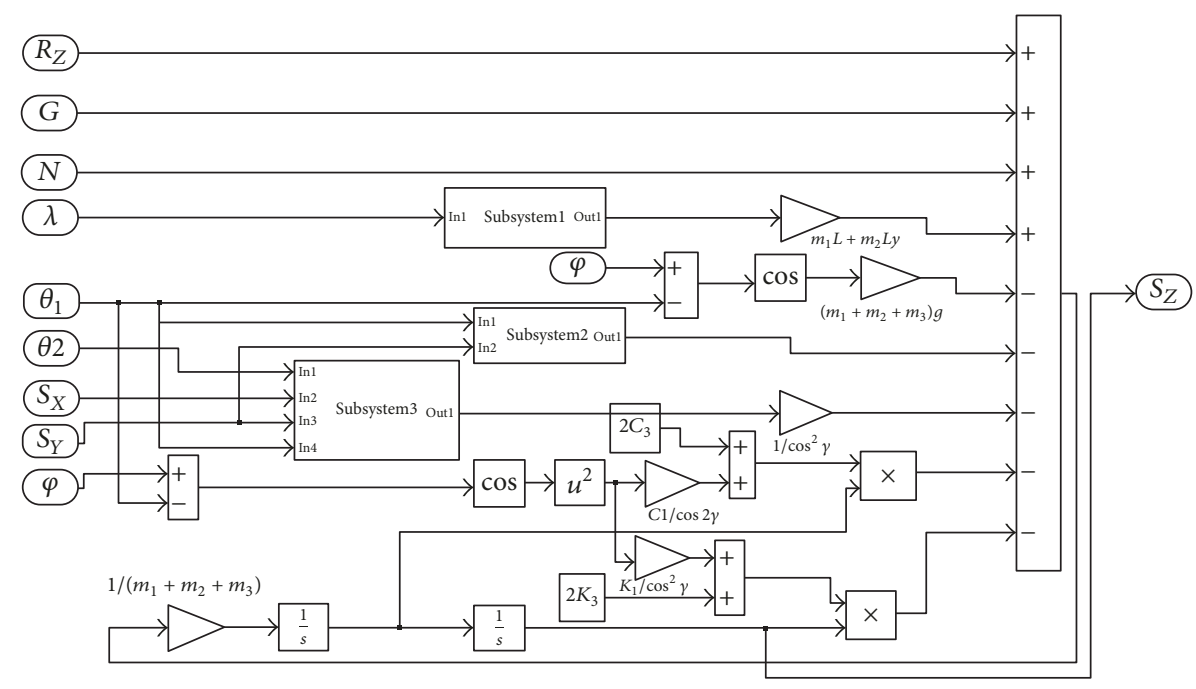

(d) The simulation model to solve $S_{Z}$

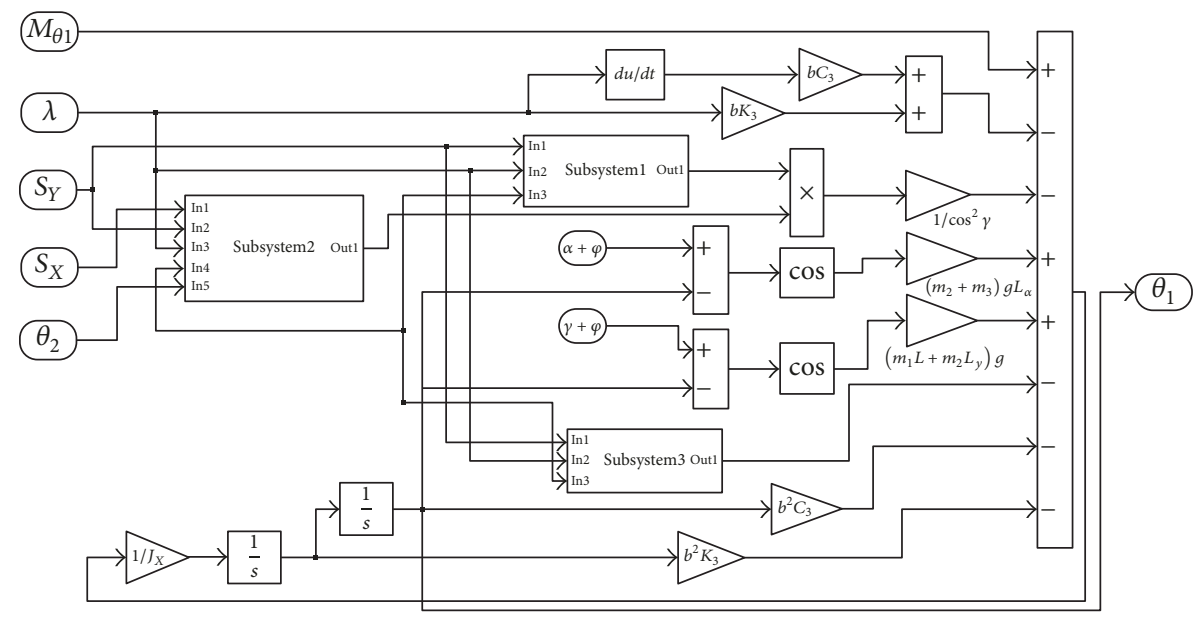

(e) The simulation model to solve $\theta_{1}$

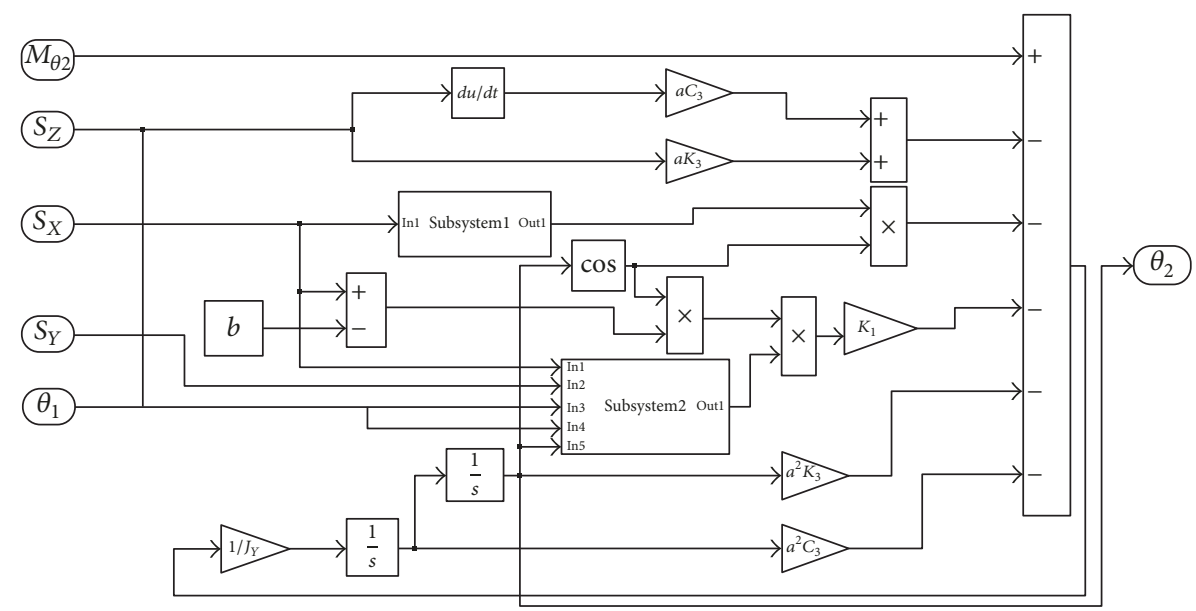

(f) The simulation model to solve $\theta_{2}$

FIgURE 10: The simulation model to solve roadheader's body pose during the horizontal cutting process. 


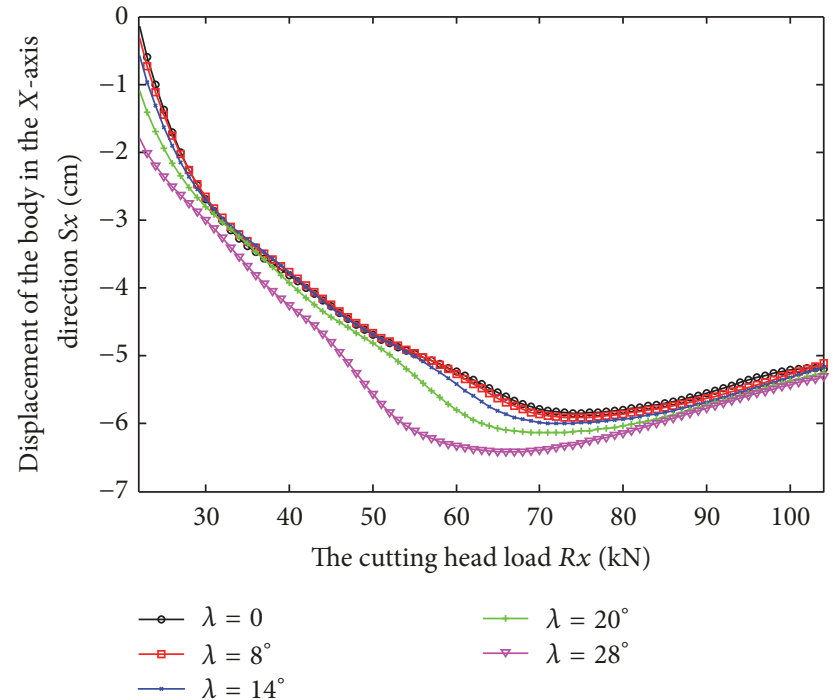

(a) The relationship between $S_{X}$ and the cutting head load in different horizontal swing angles of the cutting arm

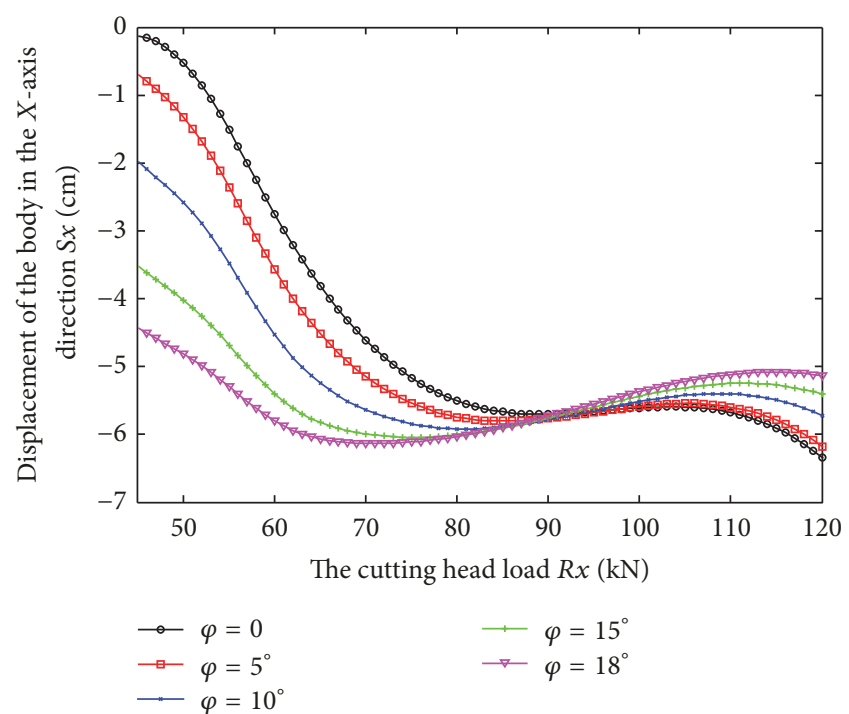

(b) The relationship between $S_{X}$ and the cutting head load in different dip angles of coal seam

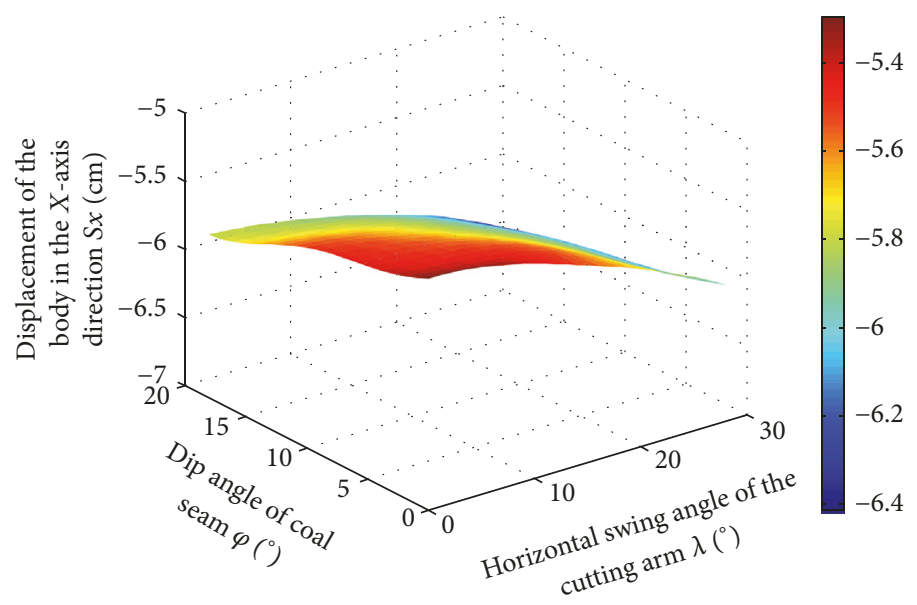

(c) The relationship of $S_{X}$, horizontal swing angle of the cutting arm and the dip angle of coal seam

FIGURE 11: The response results of displacement of the body in the $x$-axis direction $S_{X}$.

are $\varphi=0, \varphi=5^{\circ}, \varphi=10^{\circ}, \varphi=15^{\circ}$, and $\varphi=18^{\circ}$. The initial parameters of simulation are shown in Table $1[31,32]$.

4.2. Analysis of the Simulation Results. The dynamical coupling model was simulated and solved in the simulation model. The cutting head load, horizontal swing angle of the cutting arm, and dip angle of coal seam were regarded as independent variables to perform changing parameter analysis in variation of the five body pose parameters, which are displacement of the body in the $x$-axis, $y$-axis, and $z$ axis direction, pitch angle, and roll angle of the body, and the results are shown in Figures 11-15.

According to Figure 11, displacement of the body in the $x$-axis direction $S_{X}$, namely, the lateral displacement, is in the minus $x$-axis direction, and its maximum can reach up to $6.5 \mathrm{~cm}$. At different horizontal swing angles of the cutting arm and dip angles of coal seam, with the increase of the cutting head load $R_{X}, S_{X}$ basically increases linearly at first, then slightly decreases, and reaches up to the maximum when the cutting head load is in the range of $70 \sim 90 \mathrm{kN}$. With the increase of horizontal swing angle of the cutting arm, $S_{X}$ increases parabolically, and, with the increase of the dip angle of coal seam, $S_{X}$ increases parabolically as well.

According to Figure 12, displacement of the body in the $y$-axis direction $S_{Y}$, namely, the backward displacement, is in the minus $y$-axis direction, and its maximum can reach up to $5.2 \mathrm{~cm}$. At different horizontal swing angles of the cutting arm and dip angles of coal seam, with the increase of the cutting head load $R_{Y}, S_{Y}$ basically increases at first and then decreases linearly. The horizontal angle of the cutting arm has no influence on the maximum point of $S_{Y}$, and, at different horizontal swing angles of the cutting arm, $S_{Y}$ reaches up to the maximum when the cutting head load is about $40 \mathrm{kN}$. But the dip angle of coal seam has great 

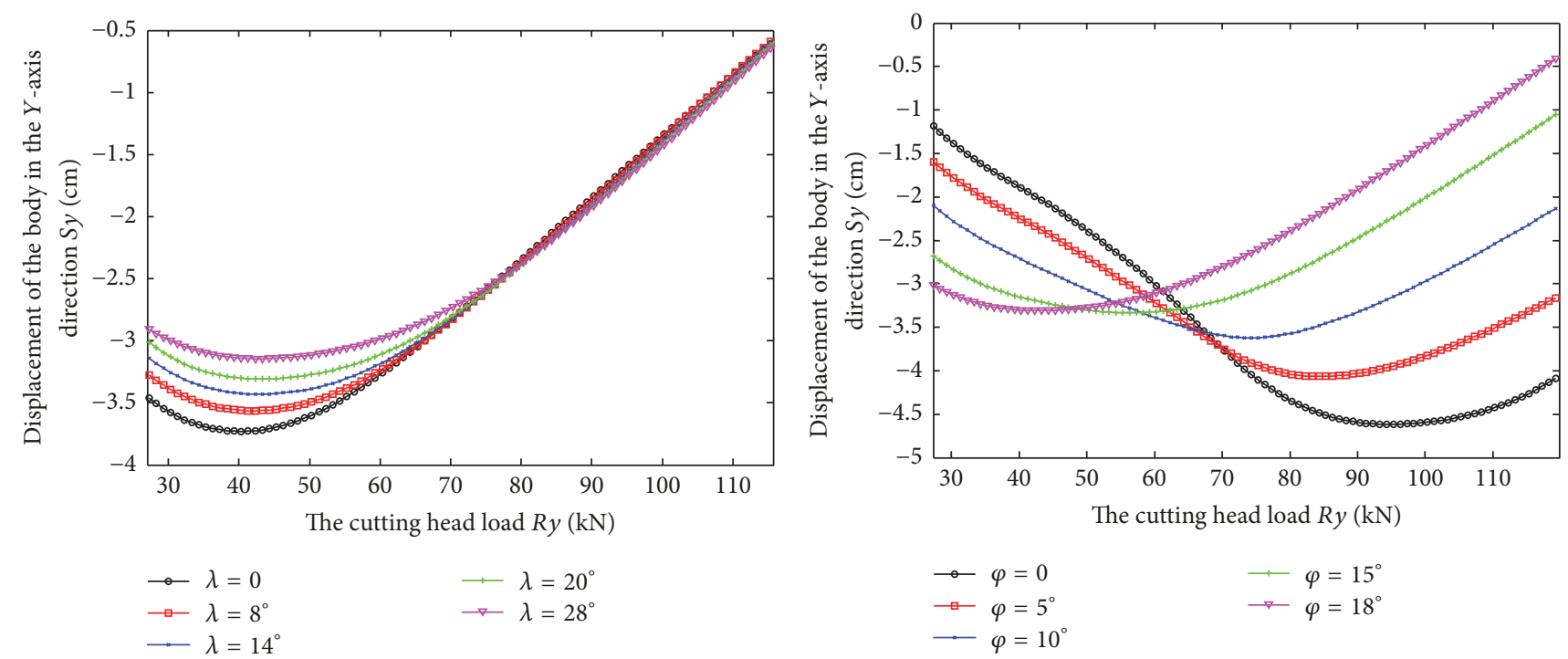

(a) The relationship between $S_{Y}$ and the cutting head load in different

(b) The relationship between $S_{Y}$ and the cutting head load in different dip horizontal swing angles of the cutting arm angles of coal seam

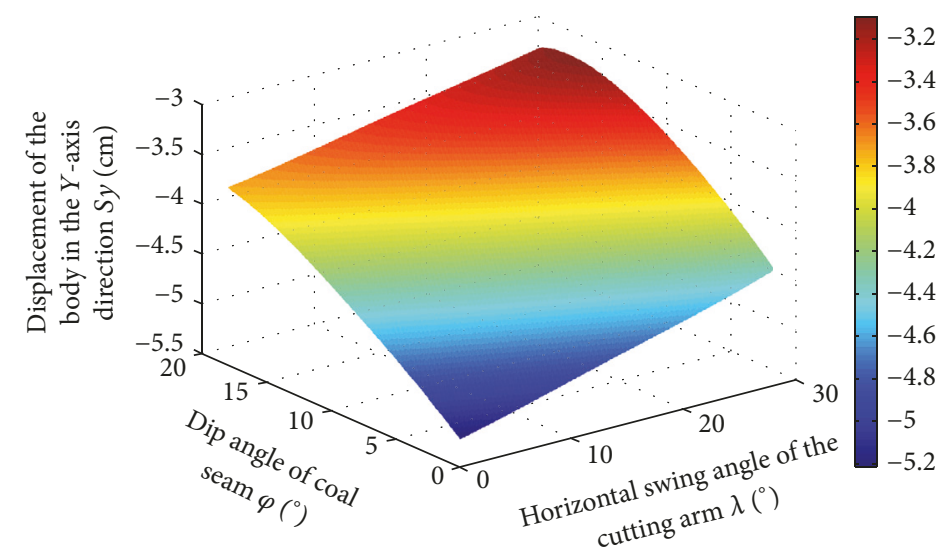

(c) The relationship of $S_{Y}$, horizontal swing angle of the cutting arm, and the dip angle of coal seam

FIgURE 12: The response results of displacement of the body in the $y$-axis direction $S_{Y}$.

TABLE 1: Initial parameters of simulation.

\begin{tabular}{lcc}
\hline Parameters & Value & Unit \\
\hline$m_{1}$ & 1600 & $\mathrm{Kg}$ \\
$m_{2}$ & 5700 & $\mathrm{Kg}$ \\
$m_{3}$ & 37700 & $\mathrm{Kg}$ \\
$K_{1}$ & $6.31 \times 10^{7}$ & $\mathrm{~N} \cdot \mathrm{m}^{-1}$ \\
$K_{2}$ & $7.45 \times 10^{6}$ & $\mathrm{~N} \cdot \mathrm{m}^{-1}$ \\
$K_{3}$ & $1 \times 10^{4}$ & $\mathrm{~N} \cdot \mathrm{m}^{-1}$ \\
$C_{1}$ & 400 & $\mathrm{~N} \cdot \mathrm{s} \cdot \mathrm{m}^{-1}$ \\
$C_{2}$ & $3.49 \times 10^{4}$ & $\mathrm{~N} \cdot \mathrm{s} \cdot \mathrm{m}^{-1}$ \\
$C_{3}$ & 10 & $\mathrm{~N} \cdot \mathrm{s} \cdot \mathrm{m}^{-1}$ \\
$J_{X}$ & 118123 & $\mathrm{Kg} \cdot \mathrm{m}^{2}$ \\
$J_{Y}$ & 25381 & $\mathrm{Kg} \cdot \mathrm{m}^{2}$ \\
$a$ & 1.15 & $\mathrm{~m}$ \\
$b$ & 2.95 & $\mathrm{~m}$ \\
$L$ & 3.9 & $\mathrm{~m}$ \\
$L_{y}$ & 1.75 & $\mathrm{~m}$ \\
\hline
\end{tabular}

influence on the maximum point of $S_{Y}$, and, at different dip angles of coal seam, the cutting head load $R_{Y}$ corresponding to the maximum point of $S_{Y}$ is in the range of about $40 \sim 95 \mathrm{kN}$, and as the dip angle of coal seam is greater, the cutting head load $R_{Y}$ corresponding to the maximum point of $S_{Y}$ is smaller. With the increase of horizontal swing angle of the cutting arm, $S_{Y}$ decreases linearly, and, with the increase of the dip angle of coal seam, $S_{Y}$ decreases parabolically.

According to Figure 13, displacement of the body in the $z$-axis direction $S_{Z}$, namely, the floor-based quantity, is in the minus $z$-axis direction, and its maximum can reach up to $11 \mathrm{~cm}$. At different horizontal swing angles of the cutting arm and dip angles of coal seam, when the cutting head load $R_{Z}$ is less than $70 \mathrm{kN}$, with the increase of the cutting head load $R_{Z}, S_{Z}$ increases linearly, and when the cutting head load $R_{Z}$ is more than $70 \mathrm{kN}, S_{Z}$ still increase linearly, but the gradient is significantly decreased. With the increase of horizontal swing angle of the cutting arm, $S_{Z}$ increases 


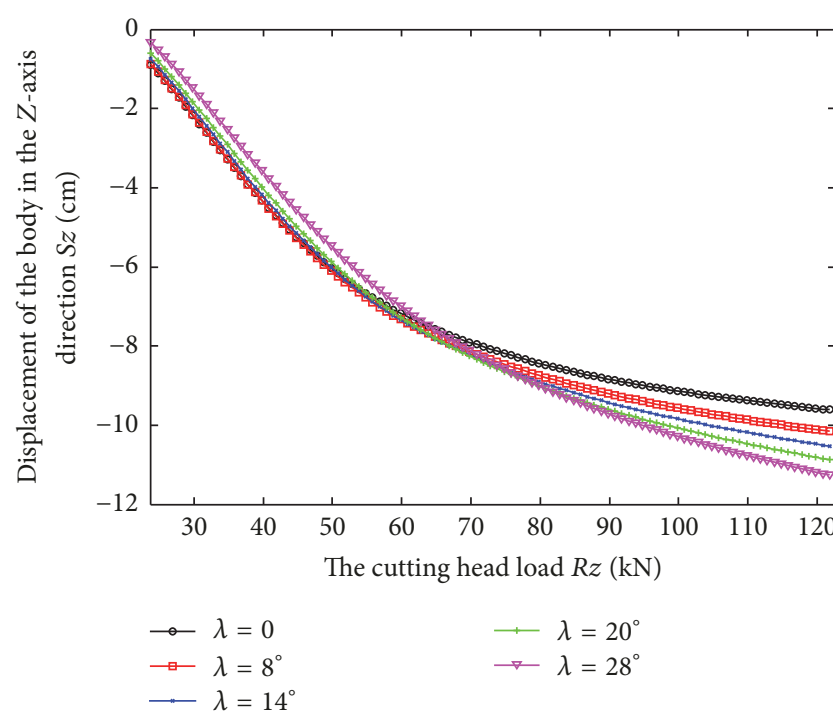

(a) The relationship between $S_{Z}$ and the cutting head load in different horizontal swing angles of the cutting arm

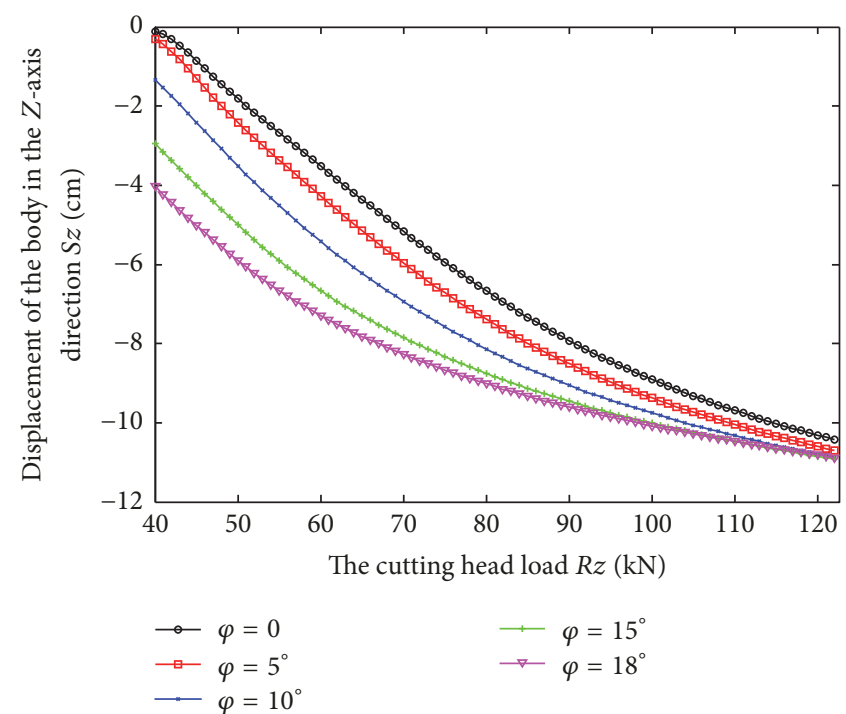

(b) The relationship between $S_{Z}$ and the cutting head load in different dip angles of coal seam

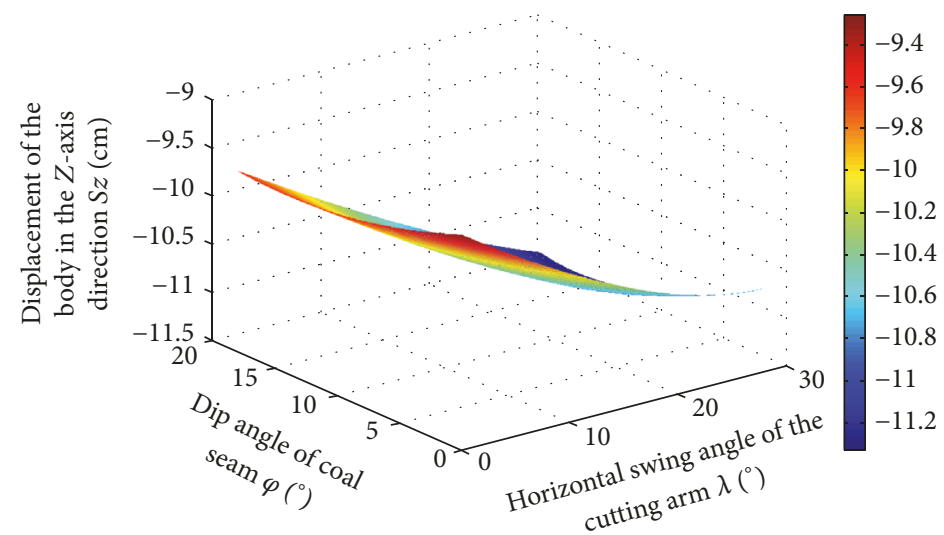

(c) The relationship of $S_{Z}$, horizontal swing angle of the cutting arm, and the dip angle of coal seam

FIGURE 13: The response results of displacement of the body in the $z$-axis direction $S_{Z}$.

parabolically, and, with the increase of the dip angle of coal seam, $S_{Z}$ increases parabolically as well, but its amplitude of variation is smaller.

According to Figure 14, pitch angle of the body $\theta_{1}$ is in the $-Z O Y$ plane and its maximum can reach up to $7.8^{\circ}$. At different horizontal swing angles of the cutting arm and dip angles of coal seam, with the increase of the cutting head load $R_{Z}, \theta_{1}$ decreases linearly. With the increase of horizontal swing angle of the cutting arm, $\theta_{1}$ increases linearly, but its amplitude of variation is relatively small, and, with the increase of the dip angle of coal seam, $\theta_{1}$ decreases parabolically.

According to Figure 15, roll angle of the body $\theta_{2}$ is in the $-Z O X$ plane, and its maximum can reach up to $2.1^{\circ}$. At different horizontal swing angles of the cutting arm and dip angles of coal seam, with the increase of the cutting head load $R_{Z}, \theta_{2}$ decreases parabolically. With the increase of horizontal swing angle of the cutting arm, $\theta_{2}$ basically increases linearly, but its amplitude of variation is relatively small, and, with the increase of the dip angle of coal seam, $\theta_{2}$ decreases parabolically.

\section{Experimental Research}

EBZ160 type roadheader is selected to conduct field experiments in YunJiaLing mine, the depth of which is between 580 and $1200 \mathrm{~m}$. Environments and conditions of the fully mechanized excavation face are highly representative, so it is suitable for experiments.

BYD-60 type mining explosion-proof pressure transmitter is selected to detect the pressure of the driving cylinders. Intrinsic safety type GUC360 mining angle sensor is selected to detect the vertical swing angle of the cutting arm. W18LD type dual speed sensor is selected to detect the horizontal swing angle of the cutting arm. TS15-A type explosion-proof automatic total station with high precision 

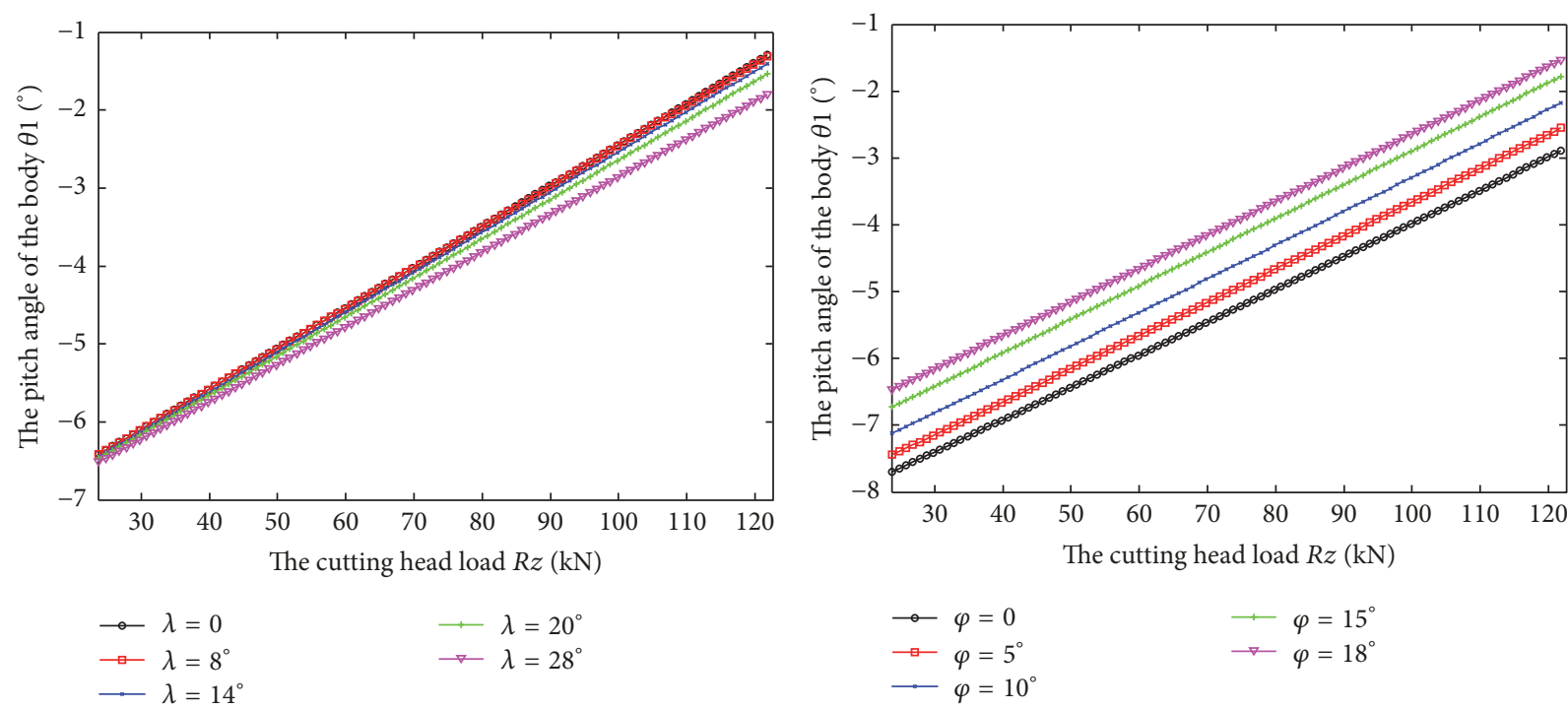

(a) The relationship between $\theta_{1}$ and the cutting head load in different horizontal swing angles of the cutting arm

(b) The relationship between $\theta_{1}$ and the cutting head load in different dip angles of coal seam

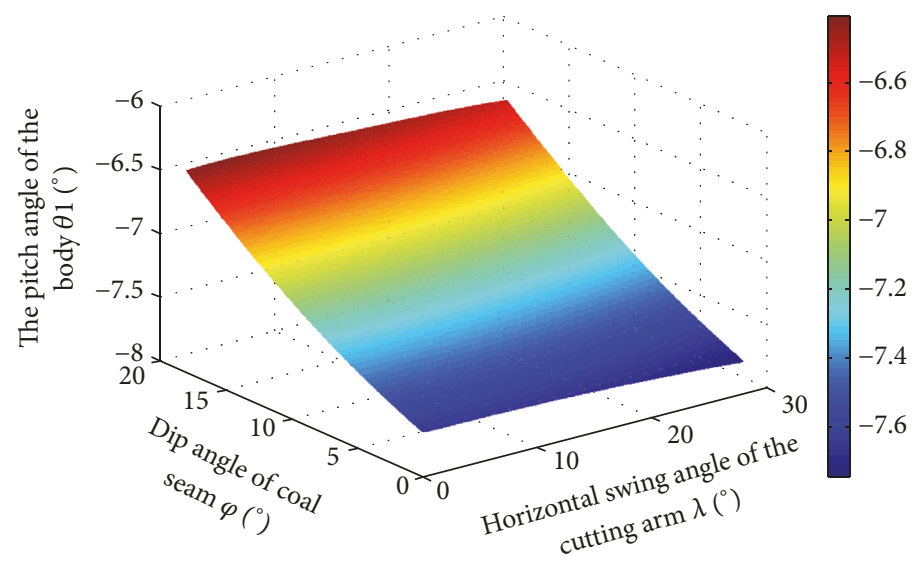

(c) The relationship of $\theta_{1}$, horizontal swing angle of the cutting arm and the dip angle of coal seam

FIgURE 14: The response results of the pitch angle of the body $\theta_{1}$.

is selected to measure the pose of roadheader. All the detected data are stored in the onboard large-capacity data recorder. The pictures of experiment equipment are shown in Figure 16.

While measuring the horizontal swing angle of the cutting arm, two arc-shaped steel racks are installed in the inside torus of the revolving platform. One rack is fixed, and the other one rotates with the revolving platform. The tooth width of the rack is $4 \mathrm{~mm}$, corresponding to $1^{\circ}$ of horizontal swing angle of the cutting arm. The sensitive surface of W18LD type dual speed sensor faces the rack, and the range of reaction is $0 \sim 2 \mathrm{~mm}$, as shown in Figure 17. With rotation of the revolving platform, the dual speed sensor can directly output horizontal swing angle signal of the cutting arm.

While measuring the roadheader's body pose, a round prism was fixed on the upper surface of the body above the center of gravity of roadheader and the automatic total station was set behind the roadheader at a certain distance. Before the cutting operation, the three-dimensional coordinate of the prism in the coordinate system of the total station was measured by the total station and expressed by $P_{0}\left(x_{0}, y_{0}, z_{0}\right)$. During the cutting process, the three-dimensional coordinate of the prism was measured and expressed by $P_{i}\left(x_{i}, y_{i}, z_{i}\right)$. A series of calculations between $P_{i}\left(x_{i}, y_{i}, z_{i}\right)$ and $P_{0}\left(x_{0}, y_{0}, z_{0}\right)$ was carried out, and variations of roadheader's body pose were obtained as follows:

$$
\begin{aligned}
& S_{X}=x_{i}-x_{0}, \\
& S_{Y}=y_{i}-y_{0}, \\
& S_{Z}=z_{i}-z_{0},
\end{aligned}
$$



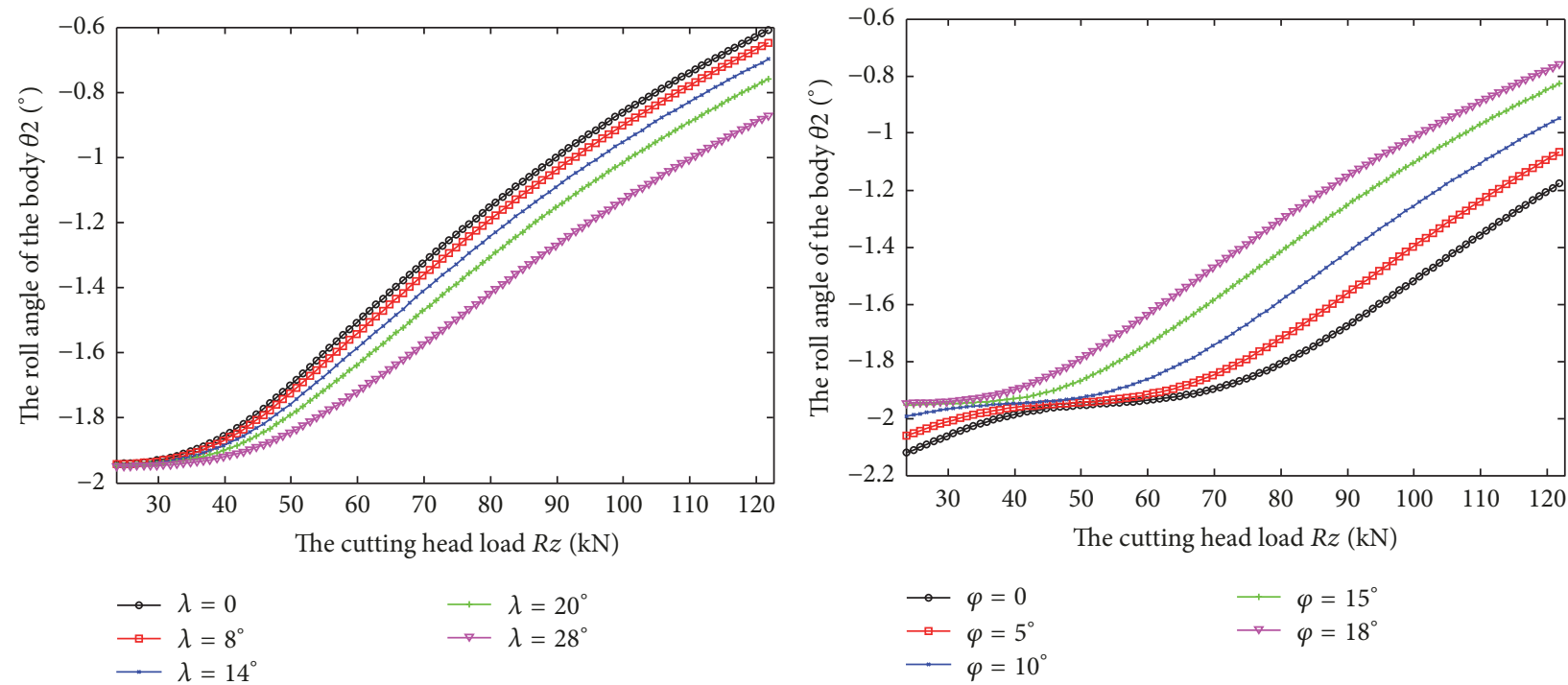

(a) The relationship between $\theta_{2}$ and the cutting head load in different horizontal swing angles of the cutting arm

(b) The relationship between $\theta_{2}$ and the cutting head load in different dip angles of coal seam

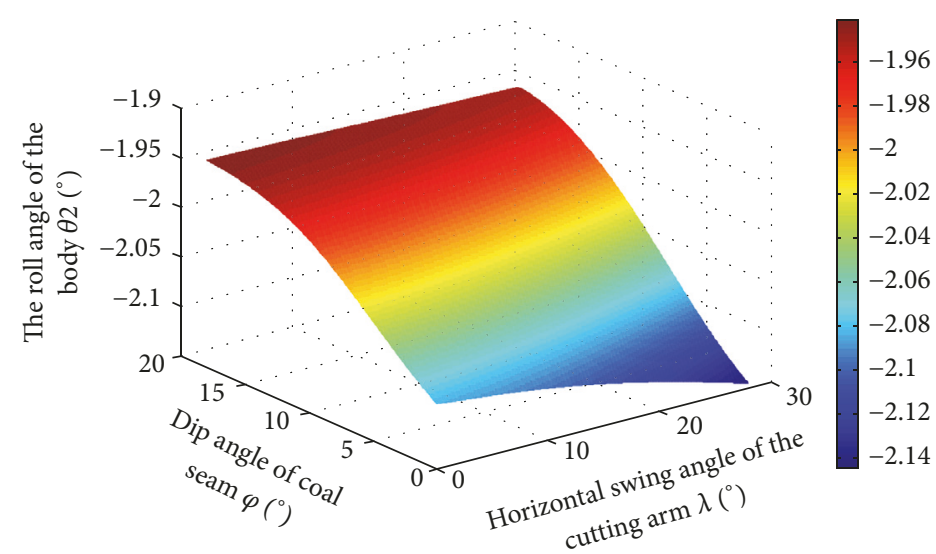

(c) The relationship of $\theta_{2}$, horizontal swing angle of the cutting arm, and the dip angle of coal seam

FIGURE 15: The response results of the roll angle of the body $\theta_{2}$.

$$
\begin{aligned}
\theta_{1} & =\arctan \frac{z_{i}-z_{0}}{y_{i}-y_{0}}, \\
\theta_{2} & =\arctan \frac{z_{i}-z_{0}}{x_{i}-x_{0}} .
\end{aligned}
$$

Pressure of the driving cylinders and swing angle of the cutting arm during the cutting process were detected by the sensors. According to the calculation method of the cutting head load in Section 3, the cutting head load was calculated and processed with the pose data of roadheader, as shown in Figure 18.

According to Figure 18, the experiment results of roadheader's body pose are basically consistent with the simulation results both in data and in changing trend. The regularities of roadheader's body pose responses during the horizontal cutting process are verified experimentally.

\section{Conclusions}

In this paper, a calculation method of the cutting head load is proposed, and the relationship between the cutting head load and pressure of the driving cylinders and swing angle of the cutting arm was obtained. Based on the experimental data of pressure of the driving cylinders, the spectrum of cutting head load was obtained.

Based on the Lagrange equation method, the dynamical coupling model of roadheader's body pose during the horizontal cutting process and the corresponding simulation model were established. The dynamical coupling model was simulated and solved, and the regularities of roadheader's 


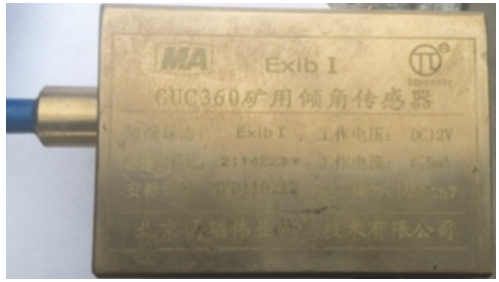

(a) Angle sensor

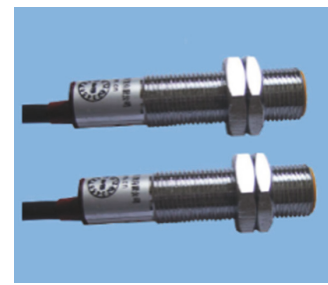

(b) Dual speed sensor

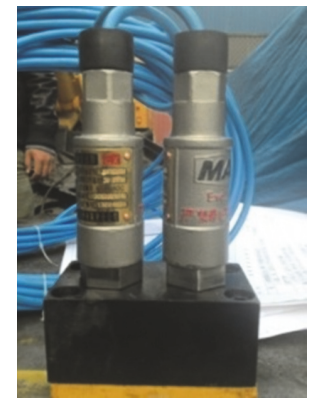

(c) Pressure transmitter

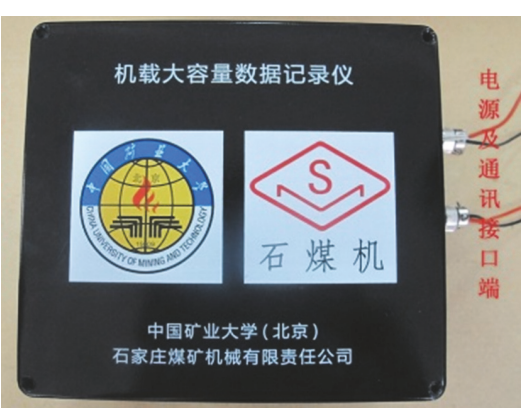

(d) Onboard large-capacity data recorder

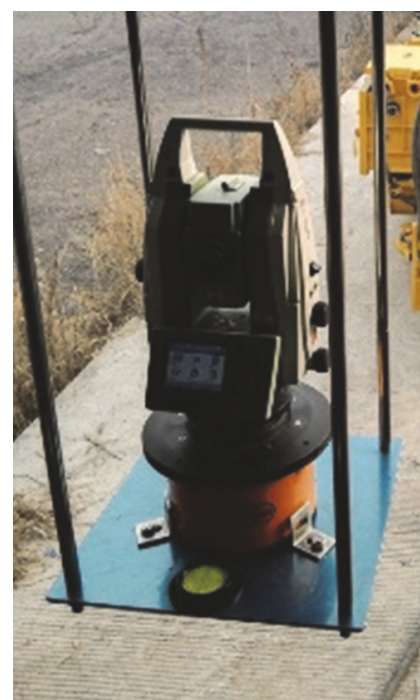

(e) Automatic total station

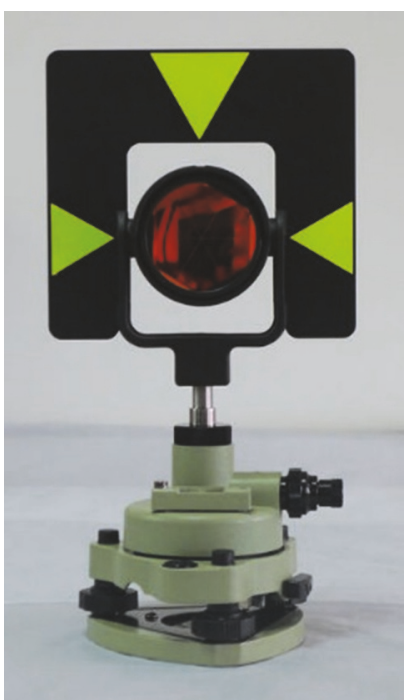

(f) Round prism

Figure 16: The pictures of the experiment equipment.

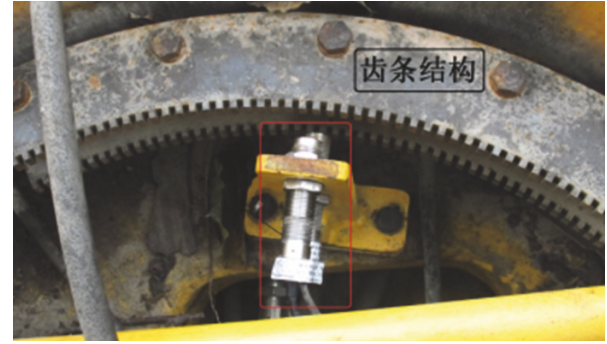

(a) Installation position

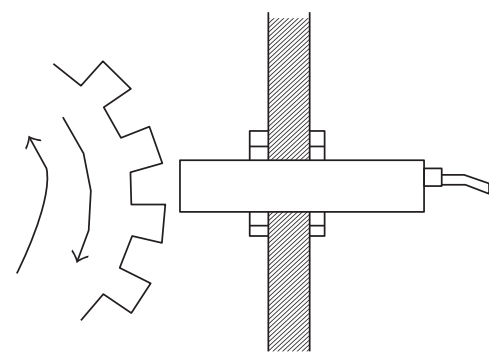

(b) Measurement schematic diagram

FIGURE 17: Installation position of dual speed sensor and measurement schematic diagram.

body pose responses influenced by different factors during the horizontal cutting process were obtained through the processing and changing parameter analysis of the simulation results. Finally, the simulation results are verified through field experiment.

The cutting head load is calculated based on the pressure of the driving cylinders and swinging angle of the cutting arm, and pressure of the driving cylinders, swinging angle of the cutting arm, and the dip angle of coal seam can be detected and obtained in real time. Therefore, the regularities of roadheader's body pose responses during the horizontal cutting process can provide important theoretical basis for rectification of roadheader's body pose and control of automatic cutting operation.

\section{Conflicts of Interest}

The authors declare that there are no conflicts of interest regarding the publication of this paper. 

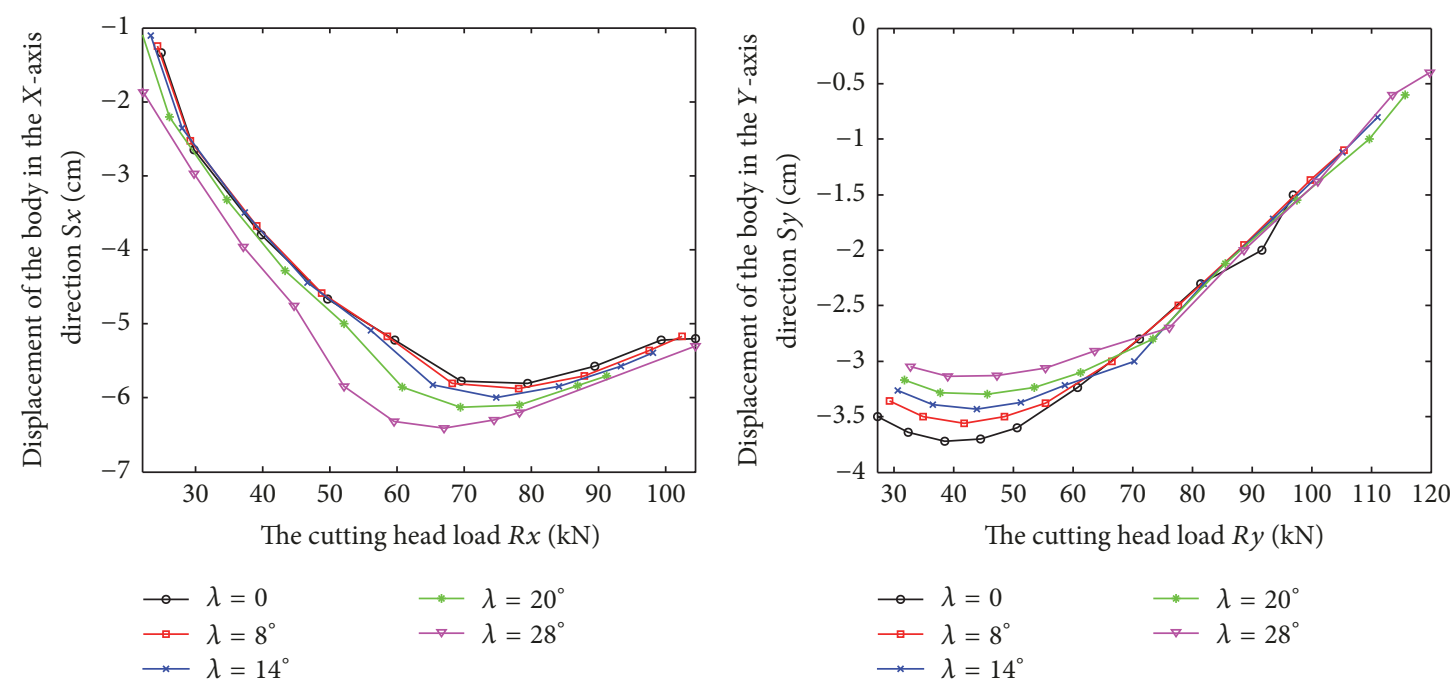

(a) Experiment result of $S_{X}$

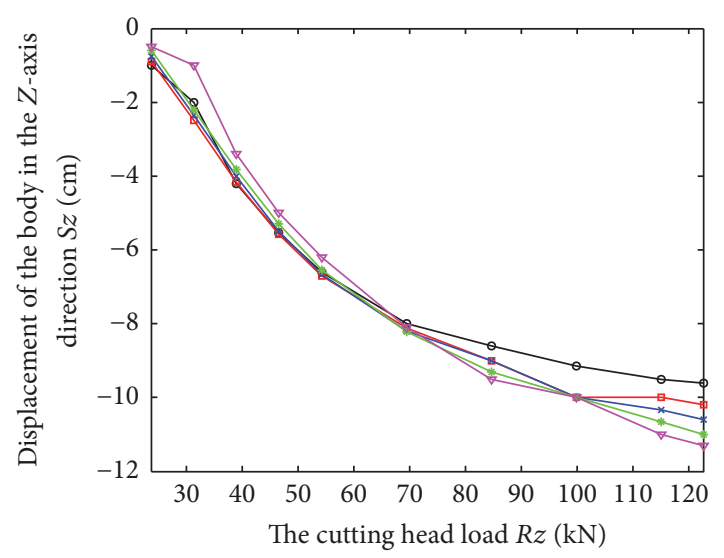

(b) Experiment result of $S_{Y}$

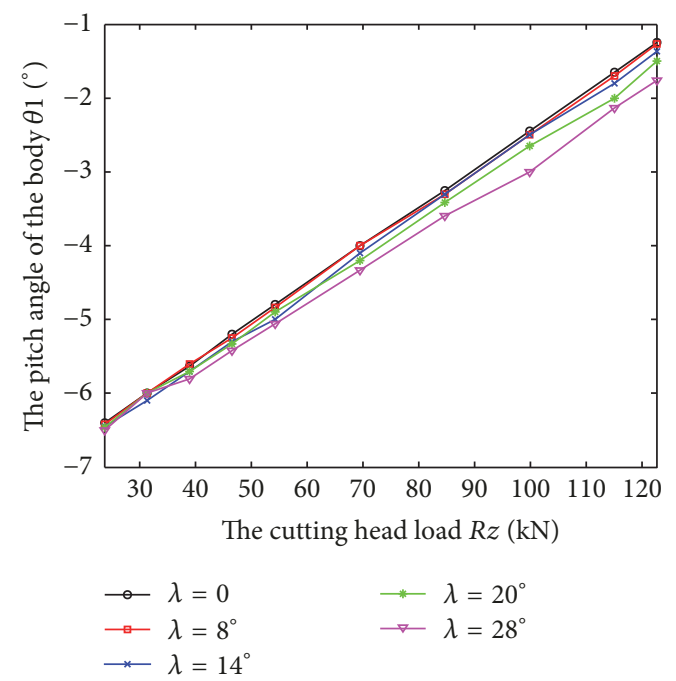

(c) Experiment result of $S_{Z}$

(d) Experiment result of $\theta_{1}$

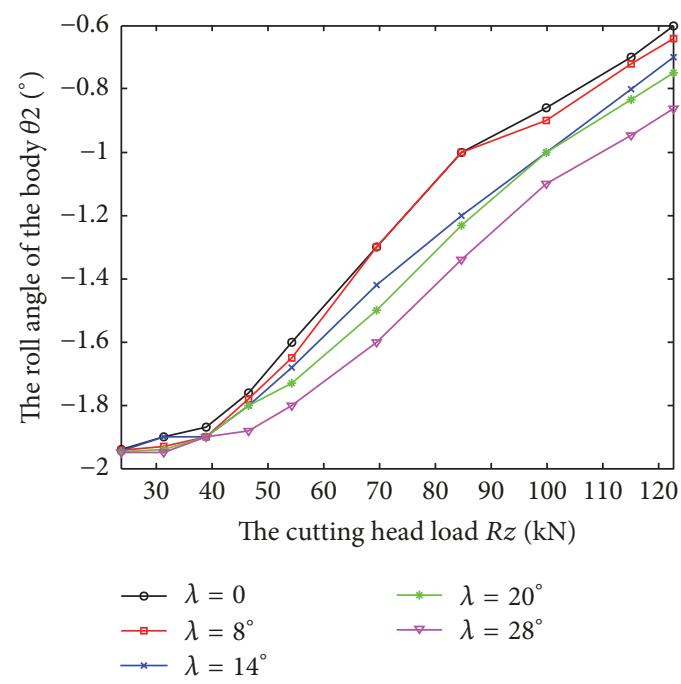

(e) Experiment result of $\theta_{2}$

FIGURE 18: The experiment results of roadheader's body pose. 


\section{Acknowledgments}

This work is supported by the National Basic Research Program of China (973 Project) (2014CB046306).

\section{References}

[1] J. Wang, "Development and prospect on fully mechanized mining in Chinese coal mines," International Journal of Coal Science and Technology, vol. 1, no. 3, pp. 253-260, 2014.

[2] C. O. Hargrave, C. A. James, and J. C. Ralston, "Infrastructurebased localisation of automated coal mining equipment," International Journal of Coal Science and Technology, vol. 4, no. 3, pp. 252-261, 2017.

[3] J. Wang, B. Yu, H. Kang et al., "Key technologies and equipment for a fully mechanized top-coal caving operation with a large mining height at ultra-thick coal seams," International Journal of Coal Science and Technology, vol. 2, no. 2, pp. 97-161, 2015.

[4] M. WU, W. Jia, W. Hua et al., "Autonomous measurement of position and attitude of boom-type roadheader based on space intersection measurement," Journal of China Coal Society, vol. 11, pp. 2596-2602, 2015.

[5] Y. Tao, K. Zong, M. Zhang et al., "Aposition and orientation measurement method of single-station,multipoint and timesharing forroadheaderbody based on iGPS," Journal of China Coal Society, vol. 11, pp. 2611-2616, 2015.

[6] S. Fu, Y. Li, J. Yang et al., "Research on autonomous positioning and orientation method of roadheader based on Ultra Wideband technology," Journal of China Coal Society, vol. 11, pp. 2603-2610, 2015.

[7] M. Dolipski, P. Cheluszka, and P. Sobota, "Investigating the simulated control of the rotational speed of roadheader cutting heads, relating to the reduction of energy consumption during the cutting process," Journal of Mining Science, vol. 51, no. 2, pp. 298-308, 2015.

[8] Y. Chen, A. Lu, X. Mao, M. Li, and L. Zhang, "Nonlinear dynamics mechanism of rock burst induced by the instability of the layer-crack plate structure in the coal wall in deep coal mining," Shock and Vibration, vol. 2017, Article ID 4051967, 12 pages, 2017.

[9] H. Wang, D. Sun, and D. Qin, "A new continuously variable transmission system applied to transmission system of the roadheader's cutting unit," Proceedings of the Institution of Mechanical Engineers, Part C: Journal of Mechanical Engineering Science, vol. 231, no. 19, pp. 3590-3600, 2017.

[10] Li xiao-H., He Y., Li T., and Yang T., "Analysis of horizontal and vertical random vibration responses of longitudinal roadheader," Journal of China Coal Society, vol. 03, pp. 580-585, 2014.

[11] X. Li, B. Huang, G. Ma, and Q. Zeng, "Study on roadheader cutting load at different properties of coal and rock," The Scientific World Journal, vol. 2013, Article ID 624512, 8 pages, 2013.

[12] Yang J., Fu S., Jiang H., and etal., "Recognition of cutting hardness of coal rock properties based on fuzzy criteria," Journal of China Coal Society, vol. S3, pp. 540-545, 2015.

[13] H. Wang, D. Wang, W. Ren, X. Lu, F. Han, and Y. Zhang, "Application of foam to suppress rock dust in a large crosssection rock roadway driven with roadheader," Advanced Powder Technology, vol. 24, no. 1, pp. 257-262, 2013.

[14] J. Mu, Y. B. Du, R. Li, J. Tian, and M. Wu, "Study on the Section's Extreme Position of Roadheader's Cutting Arm in Coal Mine
Laneway," Applied Mechanics and Materials, vol. 88-89, pp. 5-9, 2011.

[15] Z. Liu, C. Du, H. Jiang, and K. Liu, "Analysis of Roadheader for Breaking Rock Containing Holes under Confining Pressures," Energies, vol. 10, no. 12, p. 1154, 2017.

[16] X. Li, Y. Lv, S. Xu, Q. Zeng, and B. Huang, "Optimization design for roadheader cutting head by orthogonal experiment and finite element analysis," Tehnički vjesnik, vol. 23, no. 3, pp. 707714, 2016.

[17] H. Ergin and O. Acaroglu, "The effect of machine design parameters on the stability of a roadheader," Tunnelling and Underground Space Technology, vol. 22, no. 1, pp. 80-89, 2007.

[18] O. Acaroglu and C. Erdogan, "Stability analysis of roadheaders with mini-disc," Tunnelling and Underground Space Technology, vol. 68, pp. 187-195, 2017.

[19] J.-S. Jang, W.-S. Yoo, H. Kang et al., "Cutting head attachment design for improving the performance by using multibody dynamic analysis," International Journal of Precision Engineering and Manufacturing, vol. 17, no. 3, pp. 371-377, 2016.

[20] H.-Y. Chen, Y. Ma, J. Mao, and Y. Zhang, "Multi-body dynamics analysis on drilling manipulator of roadheader," Meitan Xuebao/Journal of the China Coal Society, vol. 38, no. 8, pp. 14841489, 2013.

[21] X. Li, He Y., Li T., and Yang T., "Analysis of horizontal and vertical random vibration responses of longitudinal roadheader," Journal of China Coal Society, vol. 03, pp. 580-585, 2014.

[22] L.-J. Zhao, Z. Tian, Y. Sun, and Z.-H. Zhou, "Vibration characteristics of a longitudinal roadheader," Journal of Vibration and Shock, vol. 32, no. 11, pp. 17-20, 2013.

[23] Y. Du, M. Tong, T. Liu, and H. Dong, "Visual measurement system for roadheaders pose detection in mines," Optical Engineering, vol. 55, no. 10, Article ID 104107, 2016.

[24] S. Fu, Y. Li, M. Zhang, K. Zong, L. Cheng, and M. Wu, "Ultrawideband pose detection system for boom-type roadheader based on Caffery transform and Taylor series expansion," Measurement Science and Technology, vol. 29, no. 1, p. 015101, 2018.

[25] R. Shirani Faradonbeh, A. Salimi, M. Monjezi, A. Ebrahimabadi, and C. Moormann, "Roadheader performance prediction using genetic programming (GP) and gene expression programming (GEP) techniques," Environmental Earth Sciences, vol. 76, no. 16, article no. 584, 2017.

[26] M. Dolipski, P. Cheluszka, P. Sobota, and E. Remiorz, "New computer simulation procedure of heading face mining process with transverse cutting heads for roadheader automation," Archives of Mining Sciences, vol. 62, no. 1, pp. 83-104, 2017.

[27] X. Lu, D. Wang, C. Xu, C. Zhu, and W. Shen, "Experimental investigation and field application of foam used for suppressing roadheader cutting hard rock in underground tunneling," Tunnelling and Underground Space Technology, vol. 49, pp. 1-8, 2015.

[28] X. LI, "Study of dynamic behaviour of horizontal-axialroadheader as transverse cutting," Chinese Journal of Constructlon Machinery, vol. 1, pp. 73-75, 2005.

[29] H. Jiang, C. Du, S. Liu, L. Fu, Y. Tang, and L. P. Wang, "Numerical investigation on rock fragmentation by cutting head of roadheader based on fracture mechanics," Journal of Vibroengineering, vol. 17, no. 5, pp. 2199-2211, 2015.

[30] R. Jiang, Y.-Q. Wang, H.-T. Li, and M.-J. Yang, "A numerical simulation on the impact of coal seam dip on productivity of CBM horizontal well," Meitan Xuebao/Journal of the China Coal Society, vol. 40, pp. 151-157, 2015. 
[31] Y. Chen, The Dynamic Analysis and Simulation of Tracked Vehicles, Shenyang Ligong University, 2012.

[32] P. Wang, "Study on Stability for Transverse-cutting of Cantilevered Roadheader," Coal Mine Machinery, vol. 5, pp. 64-66, 2009. 


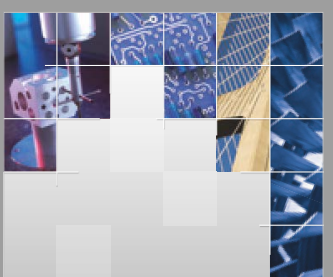

\section{Enfincering}
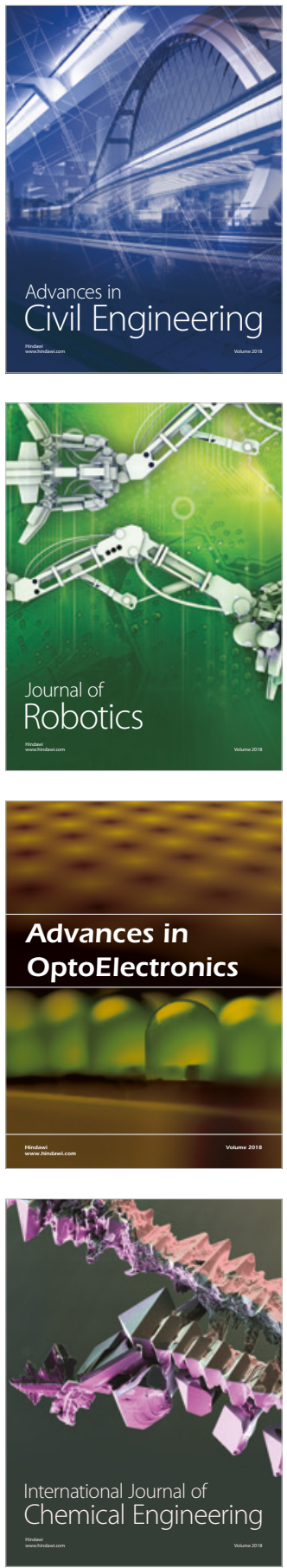

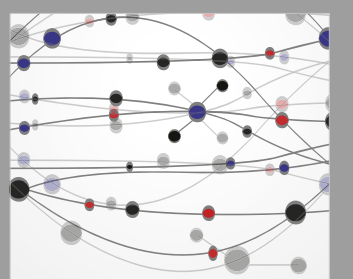

\section{Rotating \\ Machinery}

The Scientific World Journal

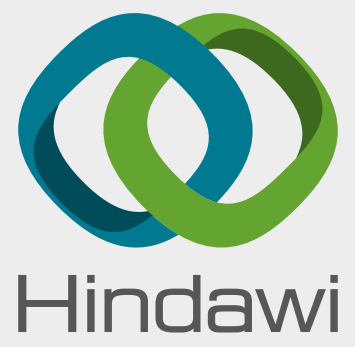

Submit your manuscripts at

www.hindawi.com
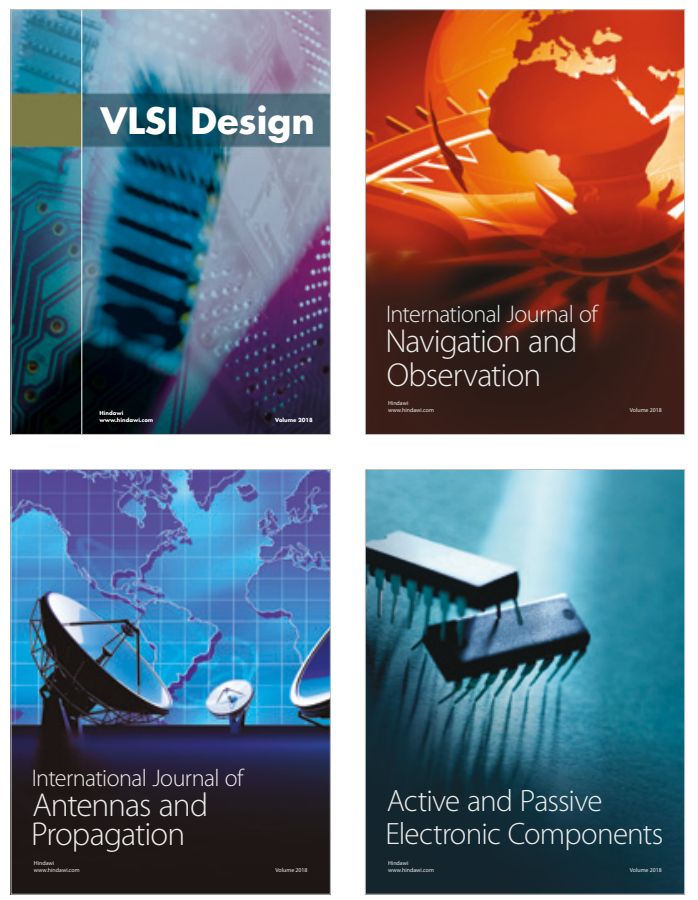
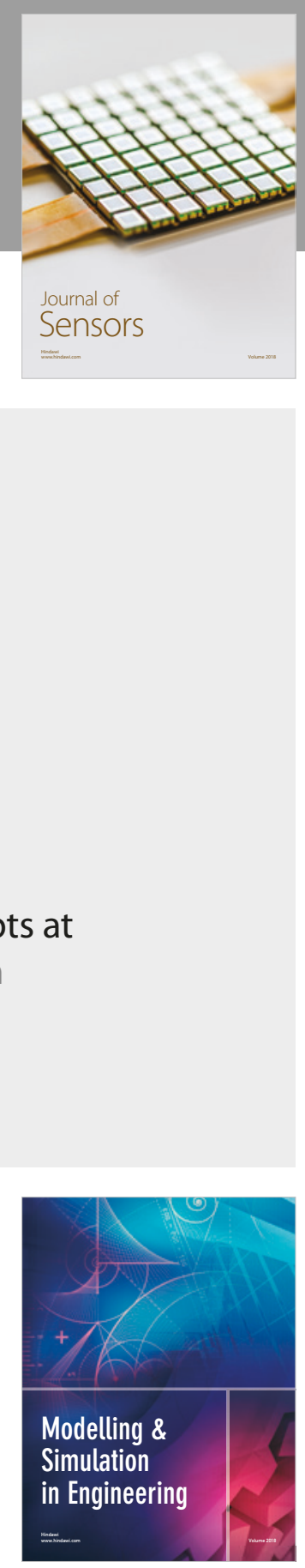

\section{Advances \\ Multimedia}
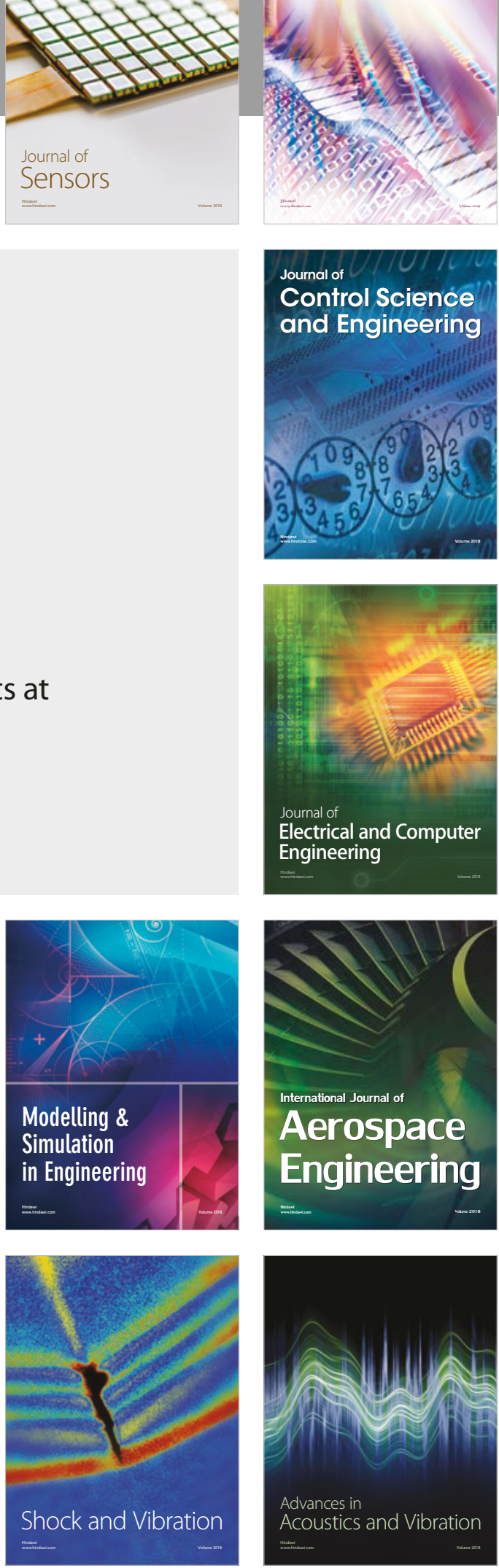